\title{
O Panorama da Internet em Cuba e uma Análise da Chegada do Google na Ilha
}

Recebido: 31-08-2019

Aprovado: 27-11-2019

Vanessa Oliveira ${ }^{1}$

Nas inúmeras discussões acerca dos usos da internet pelo mundo, é comum ver Cuba enquadrada entre os contextos autoritários, ao lado de países como a China ${ }^{2}$ e o Irã, onde a rede é oficialmente censurada. Via de regra, discute-se a internet em Cuba pela sua negação: pelo controle estatal sobre o fluxo de informações (BIDDLE, 2013: 3) ou pela incapacidade da Ilha de universalizar a rede ${ }^{3}$. São escassos os estudos mais detalhados, capazes de lançar luz sobre as particularidades do uso e da penetração, tanto da rede quanto do conteúdo virtual, no contexto específico dessa sociedade.

As generalizações acerca da internet - e da chamada "desconexão" - em Cuba turvam, por exemplo, as possibilidades de leitura crítica, mesmo por pesquisadores e agentes políticos progressistas, sobre o interesse de transnacionais como o Google, o Airbnb ou a Amazon pela Ilha. Considerando-se a polarização política que ronda qualquer debate acerca de Cuba, podese dizer que tanto defensores quanto opositores da Revolução têm seu conjunto de simplificações sobre os caminhos da conexão à internet na Ilha. Pela esquerda, é recorrente uma certa "vista grossa" sobre a carga ideológica que acompanha os conglomerados tecnológicos do Vale do Silício, como se a disponibilização do acesso fosse mais urgente do que o cálculo das implicações político-econômico-sociais de fazê-la por meio de tais empresas. E do ponto de vista conservador, o clichê mais comum é basear a crítica da precariedade de acesso em Cuba em modelos ideologicamente pré-concebidos sobre o direito

\footnotetext{
${ }^{1}$ Vanessa de Souza Oliveira, brasileira, doutora pelas universidades UFABC e Paris 8, email: nessa.souzaoliver@gmail.com

${ }^{2}$ Cf. ARSĖNE, 2011 b.

${ }^{3}$ Cuba's Internet: Censorship And High Costs Mean Web Access Will Remain Elusive For Most Cubans. Disponível em: <http://www.ibtimes.com/cubas-internet-censorship-high-costs-mean-web-access-will-remainelusive-most-cubans-2106830>. Acesso em: 23 nov. 2015
} 
individual à liberdade de expressão ${ }^{4}$. Como se o que se considera "liberdade de expressão" em países capitalistas liberais fosse um valor universal, automaticamente aplicável a contextos absolutamente díspares.

O filósofo francês Raymond Aron ${ }^{5}$ divide a liberdade em diversas subcategorias: de expressão, de circulação e de empreendimento, entre outras. Tal categorização é importante para evitar uma visão simplista de liberdade como um conceito universal e positivo por si só. Esta concepção liberal, frequentemente instrumentalizada por conservadores - talvez o melhor exemplo seja a forma como os Estados Unidos empunham o slogan da "Liberdade" em todas suas incursões militares $^{6}$-acaba por fragmentar realidades coletivas em individualidades atomizadas, dispersando o potencial transformador da luta de classes em uma confusão de lutas de todos contra todos.

Não se trata aqui de um discurso contrário à liberdade de expressão, mas da constatação de que, nas democracias representativas liberais, este direito é mediado pelo capital. Ou seja, a liberdade de expressão, ainda que propagada dentro da perspectiva liberal como uma universalidade a ser encampada e resguardada inclusive juridicamente, acaba na prática restrita a quem tem acesso a meios hegemônicos de transmissão midiática. A estrutura da internet, por ser uma rede de redes distribuídas, criou a ilusão de que era iminente uma quebra do monopólio da liberdade de expressão por parte do poder econômico ou político (no caso de países em que o Estado detém e controla os meios de comunicação). O que defendemos aqui é que esta perspectiva não sobrevive ao surgimento das redes sociais e de sua instrumentalização social, política e econômica pelos antigos detentores do monopólio informativo. Assim, o advento da internet voltou a mostrar duas coisas: 1) que a ideia liberal de liberdade de expressão universal não tem como se consolidar em uma sociedade mediada pela distribuição desigual do poder inerente ao sistema de exploração capitalista; 2) que nenhum meio tecnológico é, por si só, capaz de refundar as relações de poder dentro de uma

\footnotetext{
${ }^{4} \mathrm{https} / / /$ freedomhouse.org/report/freedom-world/2019/cuba Acesso em 05. mai.2019.

${ }^{5}$ Cf. ARON, 1965. Neste ensaio, Aron confronta Marx e Tocqueville na tentativa de entender a tensão entre liberdades formais e liberdades reais. $\mathrm{O}$ autor busca entender quais são as liberdades reconhecidas pelo Direito sem que os meios para que elas se efetivem existam e tece um manifesto pelo liberalismo político, que nada tem a ver com uma apologia ao poder auto-regulador do mercado e sua auto-regulação, mas que é propositalmente confundido com essa corrente, causando grande confusão ideológica.

${ }^{6}$ Exemplos da instrumentalização político-ideológica do conceito de Liberdade por chefes de Estado estadunidenses abundam. Mas a título ilustrativo, recordamos o discurso proferido por George W. Bush em 20 de março de 2003 ao anunciar a invasão ao Iraque, sob o pretexto (depois comprovado fraudulento) de que Saddam Hussein possuía armas de destruição em massa. As últimas linhas do texto diziam: "Defenderemos nossa liberdade. Levaremos liberdade para os outros e venceremos". A íntegra do discurso pode ser encontrada no link https://www.theguardian.com/world/2003/mar/20/iraq.georgebush (Acesso em 05.mai2019).
} 
sociedade. Em suma, defendemos que a liberdade de expressão se efetiva pela distribuição de poder (político e econômico) e não pela falsa escolha entre dois agentes autoritários - Capital e Estado - que controlam, em maior ou menor grau de aliança e coordenação, o fluxo comunicacional.

No que diz respeito a Cuba, essa perspectiva liberal do conceito de liberdade de expressão fica nítida na crítica que reduz a questão do acesso à internet ao papel do Estado como um censor, um agente do cerceamento da liberdade de expressão - que, no século XXI, é frequentemente associada à possibilidade de livre navegação pela internet. Não que não haja interesse do Estado no controle do fluxo informativo; de fato, há. Mas isso não é um diferencial cubano ou mesmo socialista. Estados ditos liberais também controlam e cerceiam fluxos informativos, seja de forma direta, seja por meio de agentes privados. Tal perspectiva, bem como outra igualmente acrítica, que enxerga a precariedade do acesso à internet como um estandarte de pureza revolucionária, acaba por impedir uma análise séria tanto das políticas oficiais sobre a rede quanto das práticas cotidianas da população cubana em relação aos usos das TICs e ao consumo de bens culturais ${ }^{7}$.

No cenário cubano, a realidade é demasiado complexa para essa leitura binária: interagem redes independentes offline, compilação e venda de filmes e outros produtos culturais baixados da internet, além de roubo e redistribuição de redes wi-fi a custo inferior ao oferecido pela estatal de telecomunicações. Esse cenário exige uma ressignificação do que é "estar conectado" em Cuba, bem como a necessidade de se reavaliar os parâmetros para entender o grau de acesso à internet no país. Para analisar o fenômeno da desconexão em Cuba, optamos aqui por analisar suas particularidades históricas. Consideramos que a crítica da desconexão em uma perspectiva de direito individual é flagrantemente anacrônica, visto que trata-se de um território cujas concepções política, histórica, econômica e ideológica não são liberais.

A pesquisadora Anidelys Rodríguez Brito recorta a história da internet em Cuba entre os anos de 1970 e 1996, avaliando-a a partir de dois pilares: o bloqueio financeiro dos Estados Unidos contra a Ilha e o chamado Período Especial - a crise econômica dos anos 1990, consequência do fim do subsídio soviético. Em uma breve linha do tempo, Brito destaca a criação, nos anos 70, de designs tecnológicos originais cubanos (uma necessidade decorrente do embargo) para a comutação de pacotes de dados no Centro de Investigações Digitais (CID)

${ }^{7}$ O conceito de bem cultural ou digital designa "um conjunto amplo e heterogêneo" de propriedade intelectual, que vai da produção artística (fotos, vídeos, música) a softwares. (Cf. ESCANDELL, 2015). 
e no Instituto de Matemática, Cibernética e Computação (IMACC). Desde os anos 80, a condição de isolamento financeiro dificultou a conexão internacional, propiciando o desenvolvimento de tecnologias para o processamento e transmissão de dados, além do surgimento de redes nacionais. Entre 1990 e 1996, conforme aprofunda-se o estrangulamento econômico e a escassez de investimentos internacionais é agravada por conta do colapso do bloco socialista, Cuba luta para manter uma posição regional destacada no que tange "a busca de alternativas para o impulso e aplicação das técnicas de internet", por meio da criação de redes de conexão para setores estratégicos, como saúde e educação ${ }^{8}$.

O engenheiro Jesús Martínez Alfonso ${ }^{9}$ detalha em texto de 1993 como a década de 1970 foi crucial para o desenvolvimento da informática na Ilha ${ }^{10}$. Amparada por investimentos externos, Cuba pôde fomentar um primeiro grupo de jovens pesquisadores que apostaram na construção de uma arquitetura de rede própria para trafegar dados, independente das que vinham sendo desenvolvidas no resto do mundo. Nesta época, o único vínculo tecnológico com o exterior aconteceu quando a equipe cubana, utilizando microprocessadores Z80 e 8080 e sistemas operacionais CP/M e, posteriormente, MSDOS, programou um protocolo de comunicação baseado nas normas internacionais da época.

Ao final daquela década, o CID e o IMACC passaram a receber aportes financeiros e parcerias acadêmicas, conforme aprofundavam-se as relações entre Cuba e os países membros do Conselho de Ajuda Mútua Econômica ${ }^{11}$ (CAME/COMECON), que possibilitou a troca de informações e o acesso a grande parte da base de dados da URSS, que fazia seu próprio esforço de desenvolvimento de redes de comunicação.

O IDICT (Instituto de Información y Documentación Científica y Técnica) e o Instituto de Sistemas Automatizados (VNIIPAS), da antiga URSS assinam em 1980, o primeiro acordo que permitia o estabelecimento de um terminal de computadores com um link de satélite sincrônico entre um país europeu e um país do Caribe, neste caso o satélite utilizado era o russo Intersputnik. Baseado neste acordo foi possível trazer para Havana a tecnologia necessária e, com expertise dos jovens técnicos cubanos, estabelecer a primeira conexão, a uma velocidade

\footnotetext{
${ }^{8} \mathrm{La}$ ruta de Internet en Cuba. Disponível em: <https://www.periodismodebarrio.org/internetencuba/2018/04/13/la-ruta-de-internet-en-cuba/>. Acesso em: 1.abr. 2019.

${ }^{9}$ Formado na Ucrânia, no início dos anos 1980, o engenheiro cubano trabalhou no Ministério de Ciência, Tecnologia e Meio Ambiente, onde dirigiu o projeto de conexão de Cuba à internet.

${ }^{10}$ Alfonso, Jesús Martínez. Una breve mirada a la Historia de la Internet Cubana | Historia de Internet en América Latina y el Caribe. Disponível em: <https://interred.wordpress.com/1993/02/12/una-breve-mirada-a-lahistoria-de-la-internet-cubana/>. Acesso em: 3 abr. 2019.
}

${ }^{11}$ CAME, também conhecida como COMECON, foi a principal organização econômica do campo socialista. Surgiu logo após a Segunda Guerra Mundial, durante uma conferência realizada em Moscou, na União Soviética, em janeiro de 1949 e teve a participação da Bulgária, Hungria, Polônia, Romênia, URSS e Checoslvaquia. CAME - EcuRed. Disponível em: <https://www.ecured.cu/CAME〉. Acesso em: 3 abr. 2019. 
de $1200 \mathrm{bps}^{12}$.

Nos anos 1980, foram desenvolvidas tecnologias para o processamento e a transmissão de dados, além da criação de redes nacionais. Alfonso cita três importantes iniciativas que marcaram o período: 1) a introdução em Cuba de "máquinas grandes"13 de processamento de dados e de minicomputadores, capazes de ampliar a capacidade e a velocidade da transmissão de informações, o que possibilitou conexões pioneiras, via satélite, entre Havana e Moscou; 2) as primeiras redes de longa distância (WAN - Wide Area Network), que garantiram a implementação de correios eletrônicos já no final daquela década; 3) a criação dos Jóvenes Clubes de Computación y Electrónica, uma rede de centros tecnológicos comunitários, que tinha como objetivo educar a sociedade cubana no uso das novas tecnologias ${ }^{14}$.

Neste mesmo relato, Alfonso conta que, em 1989, Cuba teve seu primeiro contato real com a comunidade da Internet durante a visita de técnicos estadunidenses da Rede nãogovernamental PEACENET, da APC (Association of Progressive Communication), vindos de São Francisco, Califórnia. A visita se repetiu em 1990. A ilha foi incluída nesta mesma época no Programa Regional de Desenvolvimento das Novas Tecnologias para países em desenvolvimento, garantindo a visita em abril de 1991 de Enzo Puliati, coordenador do PNUD (Programa das Nações Unidas para o Desenvolvimento) e de Teodoro Hope, criador e diretor da rede costarriquenha Huracán. Nesta fase de discussões também esteve muito próximo dos debates o brasileiro Carlos A. Afonso, à época, conselheiro do CGI, o Comitê Gestor da Internet no Brasil.

Segundo Alfonso, nesta ocasião, houve seminários e a primeira implementação, via protocolo UUCP, de um correio eletrônico conectado à Internet, especificamente ao nó principal da rede Huracán. Alfonso lembra:

O projeto deveria ser autossustentável e tinha garantido inicialmente um fundo para seis meses de operação, devendo seguir posteriormente com recursos próprios (...). Mas, quatro meses depois, os fundos acabaram, a conexão com a Costa Rica foi cancelada e começamos a fazer UUCP com o nó Web (esse era o nome) da rede APC, no Canadá. Dessa maneira, a chamada acontecia do nó WEB ao CENIAI e era a APC que assumia o custo deste nó, com o apoio de amigos de Cuba que faziam contribuições para manter a conexão. (...) Isso aconteceu até 1994, quando o nó Web desapareceu, depois de ser comprado pela companhia canadense Nirv

\footnotetext{
${ }^{12}$ bps: bytes por segundo. Medida da velocidade de transmissão de dados.

13 Alfonso explica que "nesta década a base fundamental do processamento de dados acontecia nas chamadas “máquinas grandes”, modelos soviéticos ou alemães, cópias dos famosos computadores IBM 370”. (tradução nossa)

${ }^{14} \mathrm{La}$ ruta de Internet en Disponível em: <https://www.periodismodebarrio.org/internetencuba/2018/04/13/la-ruta-de-internet-en-cuba/>. Acesso em: 1 abr. 2019.
} 
Center. A partir daí, se estabelecem relações contratuais entre esta empresa e o IDICT $^{15}$. (tradução nossa)

Paralelamente, os Estados Unidos se mobilizavam para utilizar geopoliticamente a genuína preocupação cubana com a desconexão. Em 1992, o presidente George Bush (pai) assinou a Lei Torricelli (Cuban Democracy Act) que buscava atualizar os métodos de penetração da política estadunidense na Ilha, tornando a ingerência mais discreta. A decisão culminou na facilitação da venda de serviços e equipamentos de telecomunicações para $\mathrm{Cuba}^{16}$. Bert Hoffman conta que:

(...) a "lei Torricelli" de 1992 pavimentou o caminho para a promoção de comunicações bilaterais individuais entre os Estados Unidos e a ilha, como forma de "buscar a transição pacífica para a democracia" (U.S. Congress 1992, Sec. 1703). Ao mesmo tempo em que reforçava as sanções dos EUA contra Cuba em outras áreas, a lei Torricelli suspendia seletivamente sanções até então existentes sobre as telecomunicações e o serviço de correios para a ilha, afirmando que: "Serviços de telecomunicações entre os Estados Unidos e Cuba devem ser permitidos. Infraestruturas de telecomunicações estão permitidas na quantidade e qualidade necessárias para providenciar serviços de telecomunicações eficientes e adequados entre os Estados Unidos e Cuba. (...) O serviço de Correios dos Estados Unidos devem tomar as ações que forem necessárias para providenciar um serviço postal direto de e para Cuba (...) (U.S. Congress 1992, Sec. 1705, e-f).

Entretanto, estava explicitamente excluído do relaxamento das sanções qualquer "investimento dos Estados Unidos na rede doméstica de telecomunicações dentro de Cuba. (ibid.)"17. (HOFFMAN, 2004, p. 157-8, tradução nossa)

Ainda que a legislação estadunidense determinasse que Washington reteria a parte correspondente à Cuba do faturamento proveniente das conexões telefônicas particulares entre

\footnotetext{
15 "Esta conexión se hacía vía llamada telefónica conmutada de larga distancia internacional y como proyecto auto-sostenible tenía garantizado inicialmente un fondo para gastos de 6 meses de operación por parte de los acuerdos firmados con el PNUD y después debía continuar con fondos propios. (...) Cuatro meses después, se agotan los fondos destinados al proyecto, se cancela la conexión por Costa Rica y comenzamos a hacer UUCP con el nodo Web (así era su nombre) de la red APC en Canadá. Esta vez la llamada se realizaba del nodo WEB a CENIAI y el costo era asumido por este nodo APC y por la solidaridad, amigos de Cuba que hacían contribuciones para que esta conexión se mantuviera. (...) Esta situación se mantuvo hasta el año 1994, cuando desaparece el nodo Web producto de una compra por la compañía canadiense Nirv Center, se establecen relaciones contractuales de servicio entre esta empresa y el IDICT.

${ }^{16}$ Cf. RECIO SILVA, 2013, p. 7.

17 "(...) the 'Torricelli Law' of 1992 opened the way to promoting individual two way communication between the United States and the island in order "to seek a peaceful transition to democracy" (U.S. Congress 1992, Sec. 1703). While reinforcing U.S. sanctions against Cuba in other areas, (...) the Torricelli law selectively lifted hitherto existing sanctions on telecommunications and postal connections to the island, stating that:

'Telecommunications services between the United States and Cuba shall be permitted. Telecommunications facilities are authorized in such quantity and of such quality as may be necessary to provide efficient and adequate telecommunications services between the United States and Cuba. (...) The United States Postal Service shall take such actions as are Cuba's necessary to provide direct mail service to and from Cuba (...)' (U.S. Congress 1992, Sec. 1705, e-f). Explicitly excluded from this easing of sanctions, however, was any U.S. 'investment in the domestic telecommunications network within Cuba' (ibid.)". (Hoffman, 2004, p. 157-8)
} 
os dois países $^{18}$, a Lei Torricelli abriu precedente para que diversas companhias estadunidenses negociassem, diretamente com o governo cubano, acordos de exploração financeira das ligações. Havana seguiu denunciando a lei como "subversão ideológica", mas, de acordo com Hoffman, o "acordo de compartilhamento de receitas acabou se tornando uma importante fonte de divisas para Cuba". (ibidem)

Esse reordenamento do bloqueio abriu precedente para que, em 1996, o OFAC (Office of Foreign Assets Control) - a agência do Tesouro Estadunidense responsável pela fiscalização das restrições econômicas do embargo - desse autorização para que a Sprint Corporation (que se fundiria à Nextel em 2005) montasse a infraestrutura necessária para que Cuba tivesse acesso à internet. A condição era que tais conexões fossem exclusivamente dedicadas à troca de informações, ficando proibida sua utilização para a realização de transações financeiras. À época, a Sprint forneceu a Cuba uma conexão satelital de 64 kbps, a um custo mensal de US\$10 mil, em um acordo que deveria obrigatoriamente ser renovado a cada mês. (Cf. RECIO SILVA, 2013, p. 7)

Um dos frutos do acordo foi a rede Infomed, uma iniciativa do Centro Nacional de Informação em Ciências Médicas que surgiu em 1991 e começou a funcionar plenamente em 1992. Este programa ambicioso, encabeçado pelo professor de comunicação Pedro Urra, tinha como objetivo garantir aos médicos cubanos acesso a artigos científicos e a um correio eletrônico que possibilitasse trocas e parcerias universitárias, em uma tentativa de segurar no país o capital humano, que emigrava maciçamente para escapar à crise dos anos $90^{19}$. $\mathrm{O}$ Período Especial havia forçado Cuba a descontinuar a publicação de milhares de livros e revistas acadêmicas, como forma de poupar recursos. A solução foi começar a pensar em caminhos para digitalizar as futuras produções e encontrar uma maneira de distribuir o material por todo o país. "Foi uma resposta concreta e histórica às necessidades de informação do sistema de saúde e à formação dos recursos humanos", comentou Urra em uma entrevista que nos concedeu em $2016^{20}$.

De acordo com Urra, a ideia inicial era "apropriar-se das tecnologias e dar um sentido

\footnotetext{
${ }^{18}$ Por mais que as comunicações entre os dois países houvessem ficado legalmente suspensas desde a entrada em vigência do embargo, a telefônica estadunidense AT\&T mantinha um cabo subaquático desde 1921, que operava ligações entre Cuba e os Estados Unidos. Washington permitiu que conexões existentes continuassem ativas, mas proibiu qualquer modernização do equipamento. Com o tempo, elas se tornaram definitivamente obsoletas: das 60 milhões de tentativas anuais de ligações apenas $1 \%$ era completado, até a entrada em vigência da Lei Torricelli. (ibidem)

${ }^{19}$ Cf. RECIO SILVA, 2014; DÍAZ ANTUNEZ, 2007; Urra GONZÁLEZ, 2011.

${ }^{20}$ Entrevista concedida à autora em 2016 por Urra González em (data?), traduzida pela autora.
} 
adaptado ao contexto do país", com soluções que fossem compatíveis à situação cubana, como a utilização de código aberto, software livre etc. Para ele, essas escolhas se basearam mais nas "circunstâncias históricas" do que em um engajamento militante por redes democráticas: "Nós optamos por usar Linux muito cedo, porque era o que melhor se adequava à flexibilidade necessária ao projeto que faríamos". Isso porque, com a assinatura da lei Cuban Liberty and Democratic Solidarity Act ou Helms-Burton Act pelo presidente democrata Bill Clinton em 1996, somou-se à proibição de que companhias estadunidenses fechassem contratos diretamente com Cuba, o estabelecimento de sanções a empresas de outros países que utilizassem tecnologia estadunidense ou que tivessem seu produto final composto por mais de $10 \%$ de material de procedência estadunidense.

Alfonso lembra que, apesar do Período Especial, o governo entendia que o investimento em tecnologia não deveria cessar:

(...) em nenhum momento se freou o desenvolvimento das duas linhas que já estavam definidas: a de transmissão de dados por comutação de pacotes ou X.25, com projetos de redes nacionais como RENACyT, CITMA e a rede de turismo SIME, além das redes UUCP e os serviços de Internet. Foi também neste ano que a empresa Telefónica Cubana, INTERTEL S.A. iniciou os trabalhos de implementação de uma rede Wan com nós x.25 na cidade de Havana com conexão internacional às grandes redes mundiais com o protocolo X.75. Essa rede, que foi batizada de CubaNet começou a ser explorada em julho de 1993 com conexões x.75 com Estados Unidos e Canadá. Com este resultado, o canal x.25, que mantinha o link do IDICT com Moscou, foi eliminado, passando a operar com a conexão da RedeCubaNet, que funcionou até agosto de 1996, quando Cuba entrou mais fortemente na Internet ${ }^{21}$. (Ibidem, tradução nossa)

O pesquisador e professor da Universidade da Califórnia Larry Press destaca que, naquele momento, Cuba era um país pioneiro no desenvolvimento da internet:

Cuba foi uma das nações caribenhas que lideraram o estabelecimento de uma rede pré-internet. A pequena comunidade de técnicos cubanos estava à frente de outros países naquele momento. Eles eram inteligentes, criativos e motivados. E acreditavam, com razão, que a internet era importante, que ela teria um impacto profundo nos indivíduos, nas organizações e na sociedade. Eles eram membros da comunidade internacional de pioneiros da internet ${ }^{22}$.

\footnotetext{
${ }^{21}(\ldots)$ en ningún momento se pararon los desarrollos que venían realizando en las dos líneas que ya estaban definidas: la de la transmisión de datos por conmutación de paquetes o X.25, con proyectos proas de redes nacionales como RENACyTen el CITMA y la Red del Turismo por el SIME, y el de las redes UUCP y los servicios de Internet. Es en este año también que la empresa Telefónica Cubana, INTERTEL S.A., inicia los trabajos de implementación de una red Wan con nodos x.25 en Ciudad de La Habana con conexión internacional a las grandes redes mundiales con protocolo X.75. Está red, que se nombró CubaNet, inició su explotación en julio de 1993 con conexiones x.75 a Estados Unidos y Canadá. Con este resultado, se elimina el canal x.25 que hasta ese entonces mantenía el IDICT con Moscú pasando a operar una conexión con la moderna Red CubaNet, que se mantuvo hasta agosto del año 1996, cuando Cuba ingresa a Internet de manera dedicada.

${ }^{22} \mathrm{Cuba}$ was one of the leading pre-Internet networking nations in the Caribbean. The small community of Cuban networking technicians was like that of other nations at the time. They were smart, resourceful, and motivated. They believed, correctly, that the Internet was important -- that it would have a profound impact on individuals, organizations and society. They were members of the international community of Internet pioneers.
} 
(PRESS, 2011, p. 1, tradução nossa)

O que aconteceu? Por que tamanho pioneirismo não se converteu na conexão física de uma Ilha de pouco mais de 11 milhões de habitantes? A pesquisadora cubana Milena Recio Silva concorda com Anidelys Brito que essa estagnação está intrinsecamente ligada a duas causas exógenas: o bloqueio comercial e financeiro imposto a Cuba pelos Estados Unidos desde 1962; e o fim da União Soviética, em 1989, que mergulhou a Ilha em uma crise econômica e social sem precedentes (RECIO SILVA, 2013).

(...) o bloqueio econômico (...) constitui uma circunstância que compromete o desenvolvimento do país, dadas as características de um mundo marcado pelas interconexões e trocas globais cada vez mais fluidas. O segundo fator de grande importância é a existência de uma crise sistêmica no seio da sociedade cubana, que começou no início dos anos 1990 e cujas sequelas ainda persistem. Diante do fim da URSS e dos "socialismos reais" europeus, aliados de Cuba, os efeitos do bloqueio se potencializaram e deixaram às claras deformações estruturais da economia cubana que haviam sido dissimuladas nas décadas anteriores pela disponibilidade de abastecimentos seguros de matéria-prima e por um regime de importações e exportações estável ${ }^{23}$. (RECIO SILVA, 2013, p. 6, tradução nossa)

Para Press, porém, a estes fatores é necessário acrescentar outro, desta vez, endógeno: a apreensão do governo em relação à livre circulação de informações, que ele chama de "dilema do ditador" - o desejo de usufruir dos benefícios da abertura da tecnologia comunicacional sem enfrentar a ameaça da instabilidade política. Como dar às pessoas acesso à informação por uma melhor saúde, educação e comércio, enquanto se bloqueia a informação política? (PRESS, 2011)

De acordo com o autor, em 1995, o governo cubano teria optado por reduzir os investimentos em infraestrutura doméstica como forma de controlar o acesso à internet; ao contrário, por exemplo, do que fez a China, que foi capaz - um esforço possível graças à sua força econômica, há que se destacar - de desenvolver mecanismos de controle da internet, ao mesmo tempo em que investia em infraestrutura e desenvolvia sua rede e empresas rapidamente ${ }^{24}$.

\footnotetext{
${ }^{23}(\ldots)$ el bloqueo económico (...) Constituye una circunstancia muy excepcional para el desenvolvimiento de un país en un mundo signado por las interconexiones e intercambios globales cada vez más fluidos. El segundo factor de importancia radical es la existencia de una crisis sistémica en la sociedad cubana, sobrevenida a principios de la década de los noventa, y cuyas secuelas aún persisten. Ante la desaparición súbita de la URSS y de los "socialismos reales" europeos, aliados de Cuba, los efectos del bloqueo se potenciaron, y dejaron al descubierto deformaciones estructurales de la economía cubana que habían sido disimuladas en décadas anteriores por la disponibilidad de suministros seguros de materias primas, y un régimen de importaciones/exportaciones estables.

24 "O poder político e as instituições públicas [chinesas] acreditaram desde o início no potencial da internet; eles investiram em redes e favoreceram a penetração delas pelo país progressivamente. Os resultados não demoraram a aparecer, e em torno da internet surgiram múltiplas empresas privadas, de pequenas a grandes, tanto no
} 
Acatamos e combinamos as duas leituras (RECIO SILVA e PRESS), para mostrar que a aceleração ou retardamento do desenvolvimento da internet em Cuba são fenômenos multifacetados. Mas acrescentamos que a (des)conexão cubana não é um fenômeno estático, dependente exclusivamente de fatores macroscópios. É possível observar uma miríade de nuances ao se analisar a profusão de soluções (oficiais ou não) surgidas ao longo de três décadas, que buscaram promover o acesso e formas populares de troca e distribuição de conteúdo.

De acordo com a medição 2017 do índice de desenvolvimento das TIC (IDT) da ONU, Cuba, apesar de ter subido 3 posições, ainda era um dos 10 países do mundo menos conectados fisicamente, ocupando a posição 166 em um ranking de 176 países $^{25}$.

A pesquisa mostra a necessidade de não confundir o isolamento geográfico da internet cubana com a inexistência de uma infraestrutura de rede. Como veremos a seguir, no caso cubano é importante distinguirmos desconexão global de desconexão local: Cuba claramente padece da primeira, mas é conectada domesticamente, como indica a curiosa pontuação. Isso porque pontua acima da média regional na subcategoria "habilidades", enquanto fica por último nas demais. Se a desconexão é tão acentuada quanto sugere o relatório, como o país tem desenvolvido tantas habilidades (capacidades de utilização da internet)? Ora, porque a desconexão não é total, ela é simplesmente isolada parcialmente de uma rede global.

\section{A Atualização do Socialismo Cubano e as Tensões em Torno da Web}

As políticas oficiais de conexão em Cuba sempre variaram entre a necessidade de apresentar soluções rápidas a problemas agudos (como a crise dos anos 1990 e o risco iminente de um êxodo de capital humano) e a tentativa de criar um fluxo de investimento

mercado das redes quanto dos serviços e, hoje, a China conta com empresas como Alibaba, Baidu, Lenovo, Huawei, Net Ease, Tencen, WeChat, Weibo, Xianomi, que são grandes líderes do setor no país e, em alguns casos, as primeiras no ranking mundial de empresas ligadas à internet e à tecnologia em geral, com investimentos em áreas variadas e inclusive, no estrangeiro, todas consideradas envolvidas em negociações bem sucedidas." Richeri, Giuseppe. "L'Internet en Chine, entre État et opinion publique », Les Enjeux de l'information et de la communication, vol. 19/1, no. 1, 2018, pp. 21-33.

25 "Cuba exibe um perfil, um Índice de Desenvolvimento da Internet (IDI) atípico, pontuando relativamente bem na sub-categoria "habilidades", mas registrando os menores resultados da região em termos de adesão a planos de celular e largura internacional de banda na sub-categoria "acesso" e de adesões a planos de banda-larga fixa, na subcategoria "utilização" ( 0,13 por 100 habitantes frente à média regional de 13,24\%). [Cuba] também tem baixíssima pontuação em número de casas com acesso à internet (7,5\%, contra média regional de 44,62\%), além de pontuação nula para acesso à banda-larga móvel . Por outro lado, Cuba mostrou avanços significativos entre o IDI 2016 e o IDI 2017, dentro desta baixa pontuação, para todos os sub-indicadores de acesso e utilização." Measuring the Information Society Report. v. 1, p. 45, 2017, tradução nossa. 
estatal importante em inovação e formação profissional de qualidade. São exemplos desta segunda faceta da política de acesso: a criação de centros especializados como a UCI (Universidad de las Ciencias Informáticas) e a CUJAE (Universidad Tecnológica José António Echeverría), em 1964, ambas focadas na formação técnica e no desenvolvimento de tecnologias; a criação do Joven Club de Computación y Eletrónica em 8 de setembro de 1987 - centros de informática, que tinham o objetivo de introduzir os alunos do ensino primário à computação; o apoio a coletivos como o Grupo de Usuarios de Tecnologias Livres (GUTL) e o Firefoxmania, ambos surgidos em 2009, com autonomia para organizar conferências internacionais e desenvolver soluções informáticas locais, o que fomentou o desenvolvimento do software livre na Ilha.

No ano 2000, o Ministério das Comunicações de Cuba teve o nome alterado para Ministério da Informática e das Comunicações para abarcar a responsabilidade sobre questões relacionadas à tecnologia e informática, e iniciou o Programa Rector para la informatización de la sociedad (PRIS), cuja missão era pensar como as novas tecnologias poderiam trazer benefícios produtivos e sociais para $\mathrm{Cuba}^{26}$. Como demonstra Hamlet López, a perspectiva do programa sobre o "paradigma da sociedade da informação ${ }^{27 "}$ " tem inspiração socialista:

\begin{abstract}
A estratégia cubana reconhece a transversalidade das TIC na vida social e econômica e seu caráter estratégico para qualquer projeto de desenvolvimento. Apesar disso, se diferencia do paradigma da sociedade da informação quando propõe um modelo focado no uso social, organizado e intensivo das TIC, que privilegia a conexão das instituições e empresas de grande importância para a sociedade. Essa lógica responde às carências econômicas e materiais que limitam a disponibilidade de equipamentos e infraestrutura no país e a uma concepção particular de desenvolvimento apoiada em fortes políticas sociais ${ }^{28}$. (LÓPEZ, 2014, p.5, tradução nossa)
\end{abstract}

Mas ainda que houvesse a intenção declarada de criar uma internet calcada nas aspirações coletivas da sociedade, Cuba enfrentava um grave gargalo: a falta de infraestrutura. Como construir uma rede de telecomunicações maciça sem utilizar nenhum componente proibido pelo bloqueio econômico? O auxílio, à época, só poderia vir de outra revolução em curso na América Latina, a Bolivariana.

\footnotetext{
${ }^{26}$ LÓPEZ, 2014.

${ }^{27}$ CASTELLS, 1999.

${ }^{28} \mathrm{La}$ estrategia cubana reconoce la transversalidad de las TIC en la vida social y económica y su carácter estratégico para cualquier proyecto de desarrollo. Sin embargo, se diferencia del paradigma de la sociedad de la información cuando propone un modelo enfocado hacia el uso social, ordenado e intensivo de las TIC, que privilegia la conexión a Internet de las instituciones y empresas con un alto impacto en la sociedad. Esta lógica responde a las carencias económicas y materiales que limitan la disponibilidad de equipos e infraestructura en el país, y a una concepción particular del desarrollo apoyada en fuertes políticas sociales.
} 
Em 2008, o Wikileaks vazou um documento assinado em 2006 pelo presidente da CVG Telecom da Venezuela, o engenheiro Julio Durán Malaver e pelo também engenheiro Maimir Mesa Ramos (atual ministro das Comunicações de Cuba; à época, diretor de Desenvolvimento e Assuntos Regulatórios da ETECSA), para a construção de um cabo de fibra ótica que conectaria Cuba à Venezuela. De acordo com o documento, ligar as costas da Venezuela às de Cuba era um empreendimento de "valor estratégico", já que o investimento permitiria que ambos Estados tivessem "um suporte confiável para as comunicações internacionais, sob o controle de nossos países ${ }^{29}$. . A preocupação com a soberania dos dois países no campo da comunicação está registrada no documento:

Como elemento integrador, o cabo submarino pode proporcionar às comunicações segurança e qualidade superiores às oferecidas pelos atuais serviços de satélite em combinação com as redes terrestres. Ou seja, é possível criar redes praticamente independentes das redes de cabo comerciais $^{30}$.

Pouco mais adiante, o texto destaca que "a segurança dessas comunicações governamentais dependerá do grau (de) separação" entre elas e as comerciais (idem, p.5). Para possibilitar essa separação, o texto designa o uso de interfaces IP para as conexões governamentais, "deixando aberta a possibilidade de uso de outras interfaces, de acordo com a demanda" (ibidem). Além da segurança das comunicações de Estado, a principal preocupação expressa no documento são as restrições impostas pelo embargo, que "dificultam enormemente as negociações com as empresas interessadas em construir um cabo submarino que desemboque em Cuba" (idem, p. 2):

[Considerando que] a essa situação se soma a possibilidade de agressões diretas contra o próprio cabo, será imprescindível buscar toda proteção possível na legislação internacional. Portanto, a proposta é que o cabo submarino seja construído e operado por empresas operadoras de telecomunicações internacionais legalmente estabelecidas, que deveram contrar com o máximo de proteção das organizações internacionais ${ }^{31}$. (ibidem)

Quem então assumiu o projeto foi o consórcio Alcatel-Lucent que, pago pela

\footnotetext{
${ }^{29}$ RECIO SILVA, 2013.

${ }^{30}$ Como elemento integrador el cable submarino puede proporcionar comunicaciones seguras y con mayores prestaciones que las proporcionadas por los enlaces satelitales actuales en combinación con las redes terrestres. Es decir, se pueden crear redes especiales que sean prácticamente independientes de las redes de cables comerciales. Acuerdo preliminar para la construcción de un cable submarino de fibra óptica entre Venezuela y Cuba, 2006, p. 1. Disponível em https://wikileaks.org/wiki/Fibra_optica_entre Venezuela_y_Cuba_2006. Acesso em:

$31 "(. .$.$) a esa situación se le suma la posibilidad de agres.iones directas contra el cable mismo, será imprescindible$ buscar en la legislación internacional toda la protección posible. Por tanto la propuesta es un cable submarino construido y operado por empresas operadoras de telecomunicaciones internacionales legalmente establecidas, que deberá contar con el máximo de protección de las organizaciones internacionales". (idem, p. 2)
} 
Venezuela, ligou o país a Cuba, aproveitando para conectar a Jamaica no caminho, a pedido do Parlamento de Kingston. O projeto passou cabos submarinos por uma distância de 1.552 km. A inauguração do equipamento estava prevista para 2011, mas só aconteceu em 2013. Em entrevista publicada em 22 de maio de 2012 pelo diário britânico The Guardian, Larry Press especulou que um fator determinante para o atraso foi o uso intensivo das redes por militantes anti-governo nas convulsões da chamada Primavera Árabe: "Eles têm medo. Não querem uma espécie de 'Primavera Cubana' ${ }^{32}$. A mesma reportagem afirma que

O silêncio oficial em relação ao cabo de fibra ótica instalado fez surgir outros rumores: de que o cabo estava operacional, mas vinha sendo utilizado de forma seletiva. Um blogueiro governista identificado como Yohandry Fontana escreveu ao final de 2011 que participantes de um fórum fechado sobre redes sociais relataram que [o equipamento] funcionava bem. "Um breve sumário: 1. O cabo não tem qualquer problema, está funcionando. 2. Espaços públicos de internet serão abertos na ilha. 3 . Os custos da conexão pública cairão ${ }^{33}$.

Entre 2015 e 2016, a empresa chinesa Huawei começou a vender dispositivos como tablets e celulares aos cubanos, além de investir no projeto de infraestrutura para a instalação de internet nos lares da Ilha. As novas parcerias inspiraram o ministério da Informática e das Comunicações que, no inverno de 2016, anunciou em Havana a criação do primeiro "parque tecnológico" do país. O Hola Ola, como foi batizado, é um espaço de entretenimento conectado, completamente estatal.

Enquanto ocorriam essas parcerias estratégicas, o governo cubano passava por uma série de mudanças internas, que teriam reflexo direto na condução da inovação tecnológica na Ilha. A principal delas foi a passagem de poder de Fidel Castro, que conduziu o país por mais de meio século, para seu irmão, Raúl, até então chefe das Forças Armadas. Fidel afastou-se temporariamente do comando da Revolução em 2006, por questões de saúde, e tratou o câmbio como um marco de continuidade político-ideológica. Em setembro daquele mesmo ano, Fidel proferiu o discurso de encerramento do XIX Congresso da Central de Trabalhadores Cubanos, em Havana, fazendo um balanço sobre os erros e acertos da Revolução e pedindo que os dirigentes considerassem as reclamações dos trabalhadores, por

\footnotetext{
${ }^{32}$ Disponível em: https://www.theguardian.com/technology/2012/may/22/cuba-fibre-optic-cable-mystery. Acesso em 13/08/2019

${ }^{33}$ The official silence over the fibre-optic cable that came aground last year has given rise to other rumours: that the cable is operational but being used selectively. A pro-government blogger known as Yohandry Fontana wrote at the end of 2011 that people who attended a closed forum on social networks reported it was working fine.

"Here's a brief summary: 1. The cable has no problem, it is working. 2. Public internet spaces will open on the island. 3. Costs for public connection will go down." (ibidem)
} 
menos agradáveis que fossem ${ }^{34}$.

No dia 18 de fevereiro de 2008, Fidel anunciou sua aposentadoria e ao 24 do mesmo mês, Raúl foi eleito presidente do Conselho de Estado e do Conselho de Ministros, cargos que o colocaram em posição equivalente à de chefe do Estado. Em seu discurso de posse, ele destacou a necessidade de trocar e conhecer as ideias e o pensamento contemporâneo da sociedade cubana:

Não há nenhuma razão para temer as divergências dentro de uma sociedade como a nossa (...) As melhores soluções podem vir de uma troca profunda de opiniões diferentes, se essa troca for guiada por intenções razoáveis e se as opiniões forem apresentadas de maneira responsável $^{35}$. (tradução nossa)

Companheiro de luta de Fidel desde a época da guerrilha pelo interior da Ilha, Raúl deixou pela primeira vez o comando do Exército para levar a cabo o que ficaria conhecido como o Sistema de Atualização do Socialismo Cubano. Logo após sua eleição, Raúl intensificou o debate público iniciado em 2007, ainda como presidente interino, convidando intelectuais e trabalhadores comuns a expressar quais problemas urgentes deveriam ser resolvidos para se pensar a reestruturação do país. Este processo de consulta popular ultrapassou em importância o que foi feito durante a Rectificación de errores ${ }^{36}$, quando Fidel programava uma nova centralização do poder em resposta ao Sistema de Direção e Planificação da Economia, colocado em funcionamento alguns anos antes.

De acordo com a historiadora Julia Sweig, agora havia mudança real no ar: "Raúl e outros [dirigentes] têm favorecido uma forma de discurso muito mais aberta, o que tem permitido a expressão e a discussão pública de um leque de ideias muito vasto ${ }^{37 \%}$. Tais debates públicos provocaram outras formas de intercâmbio, até então pouco correntes no país.

Um dos episódios mais emblemáticos da penetração dos meios virtuais na vida política

\footnotetext{
${ }^{34}$ Mauricio VICENT, Raúl Castro hace un discurso autocrítico sobre la Revolución, El País, 29 de setembro de 2006, Acesso em 11.out.2014.

${ }^{35}$ «There is no reason to fear discrepancies in a society such as ours, where its very nature precludes the existence of antagonistic contradictions, since the social classes that make it up are not antagonistic themselves. The best solutions can come from a profound exchange of differing opinions, if such an exchange is guided by sensible purposes and the views are uttered with responsibility », Julia SWEIG, Cuba : What Everyone Needs to Know, Oxford University Press, New York, 2008, p.215.

${ }^{36}$ O processo de Rectificação de Erros e Tendências foi lançado por Fidel em 1986 e durou até o ano de 1990 no contexto da Perestroika soviética e tinha como objetivo conter a aparição de uma classe media cubana. Foi um processo marcado pela autocrítica e pela retomada do controle de pequenos negócios privados, por exemplo, que passavam por uma breve fase de tolerância no início dos anos 1985. Cf OLIVEIRA, Cuentapropismo à Cuba : L'évolution d'une politique économique, de «mal nécéssaire » à allié du gouvernement cubain. Université Sorbonne Nouvelle, Paris III, 2014.

${ }^{37}$ « Raúl and the others promote a far more open form of discourse and permit a much greater range of ideas to be publicly discussed and reported », Ibidem.
} 
cubana foi a chamada "guerra dos e-mails" em janeiro de 2007, quando artistas cubanos promoveram um protesto virtual de extensão internacional contra uma homenagem promovida pela televisão estatal Cubavisión a Luis Pavón Tamayo, que havia comandado o Conselho Nacional de Cultura (CNC) entre 1971 e 1976, durante o chamado quinquênio cinzento, quando a censura se abateu fortemente sobre intelectuais e artistas da Ilha - não apenas sob acusações de atividade contrarrevolucionária, mas também por "desvios morais" como homossexualidade e "outras fraquezas ideológicas"38.

A aparição de Tamayo coroou uma série de revisionismos do quinquênio cinzento que vinha acontecendo desde o início de 2006, com a reabilitação, em meios oficiais de comunicação, de burocratas e censores como Jorge Serguera, ex-fiscal dos Tribunais Revolucionários e ex-diretor do Instituto Cubano de Rádio e Televisão, além de Armando Quesada, cuja função na época era o expurgo de dissidentes no meio teatral. Tão logo Tamayo apareceu no programa - que ocultou seu papel na repressão para exaltar suas "contribuições à cultura cubana" -, intelectuais de esquerda, dentro da Ilha, começaram a trocar telefonemas para articular uma resposta e exigir um pedido oficial de desculpas do governo. Conforme os diálogos tomaram a via virtual, eles se tornaram um rastilho de pólvora e extrapolaram as fronteiras nacionais, o que obrigou o Secretariado da União de Escritores e Artistas de Cuba (SUEAC) a emitir uma nota compartilhando da "justa indignação de um grupo dos nossos mais importantes escritores e artistas, como consequência de recentes transmissões (...) da televisão cubana" ${ }^{\sharp 9}$. Esta foi a primeira vez que a internet serviu não apenas como suporte, mas como catalisador da contestação interna, de esquerda, à política estatal cubana.

Como se verifica pelas trocas públicas de e-mails posteriores à nota da $\operatorname{SUNEAC}^{40}$, a classe artístico-intelectual considerou insuficiente o posicionamento oficial e deu início a um processo de escrutínio, não apenas do quinquênio cinzento, mas do atual estado da Revolução Cubana:

Os balanços críticos dos anos de chumbo (a "década cinzenta" de 1970) e a memória dos descontroles do "socialismo" real durante o Congresso da UNEAC em abril de 2008 foram os primeiros indícios deste despertar. Durante as 5 mil assembleias organizadas em centros de trabalho em 2007 se denunciou: a disparidade de recursos; o acesso ilegal a divisas; as dificuldades nos transportes públicos; a falta de professores e a precariedade de sua formação; a diminuição do número de médicos; a carência de serviços; a incompetência da administração

\footnotetext{
${ }^{38}$ https://elpais.com/diario/2007/01/13/cultura/1168642801 850215.html Acesso em 06.mai.2019.

${ }^{39}$ A íntegra da nota do Secretariado, bem como um resumo dos principais textos trocados entre intelectuais cubanos durante a "Guerra dos emails", pode ser encontrado na edição 43 da Revista Encuentros (p. 254 a 269), disponível online no endereço https://www.cubaencuentro.com/revista/revista-encuentro/archivo/43-invierno-de2006-2007/(filter)/index.

ibidem
} 
pública; e a pequena corrupção "rasteira". Expressou-se a exigência de uma maior participação popular nas decisões. As autoridades encorajaram estas críticas: "é assim que podemos avançar", se dizia dentro do partido ${ }^{41}$.

Sweig estima que essas discussões configuraram "um dos debates mais abertos e

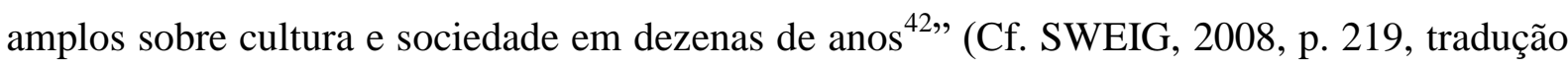
nossa). Em termos de acesso à rede, no entanto, as mudanças só puderam ser verificadas de forma mais extensa pela população depois do Primeiro Encontro Nacional de Informatização e Cibersegurança, em $2015^{43}$, quando a massificação da conexão começou a tomar corpo.

No segundo semestre de 2013, a ETECSA (Empresa de Telecomunicaciones de Cuba S.A.) iniciou a instalação de cibercafés nas principais cidades do país. Como a oferta ainda era inferior à demanda, a estatal passou a instalar alguns pontos wi-fi em praças e vias públicas, principalmente a partir de 2014. Em 2015, novos hotspots foram conectados em parques e outros espaços públicos, barateando em $25 \%$ a hora de conexão. Até o final de 2016, mais de 40 espaços públicos contavam com conexão em Havana. De acordo com dados da própria ETECSA, em março de 2019, o país contabilizava mais de 950 pontos públicos de acesso, 123 deles em Havana ${ }^{44}$.

Mas, paralelamente às soluções oficiais, a população cubana desenvolveu uma série de táticas independentes para driblar a desconexão e, acima de tudo, aceder a bens culturais/digitais. Na expectativa de reduzir os danos causados pela falta de investimentos em infraestrutura, pelo embargo ou pelos entraves à universalização das políticas, soluções criativas emergiram da própria sociedade civil. Três invenções da sociedade estão no centro do debate sobre a autonomia e a soberania cubanas no campo da comunicação em rede: $e l$ paquete semanal, a Snet e o serviço de "Connectify".

\footnotetext{
41، 'Los balances críticos de los años de plomo (la «década gris» de 1970), el recuer-do de los descontroles del «socialismo real» durante el Congreso de la Unión de losEscritores y Artistas Cubanos (UNEAC) en abril del 2008 fueron los primeros índices deese despertar. Durante las 5.000 asambleas organizadas en centros de trabajo en 2007se denunció: la diferencia de recursos; el acceso ilegal a divisas; las dificultades de lostransportes públicos; la falta de maestros y su formación deficiente; la disminución delnúmero de médicos; la carestía de los servicios; la incompetencia de los administra-dores; y la pequeña corrupción «rastrera». Se expresó la exigencia de una mayor participación popular en las decisiones. Las autoridades habían alentado estas críticas: «es así que podemos avanzar» se decía dentro del partido". Janette HABEL Raúl Castro a la hora de las decisiones, América Latina Hoy, 52, 2009, Ediciones Universidad de Salamanca, p. 99-100. http://revistas.usal.es/index.php/1130-2887/article/viewFile/5677/5712, Acesso em 05. Mai.2019.

42 « (...) most forthcoming and wide-ranging series of publicly broadcast discussions about culture and society in decades », Cf. SWEIG, 2008, p. 219.

${ }^{43}$ Resumen de las bases y prioridades para el perfeccionamiento de la informatización de la sociedad cubana. Centro de Investigaciones de Tecnologías Integradas (CITI), Instituto Superior Politécnico José Antonio Echeverría (CUJAE), I Taller Nacional de Informatización y ciberseguridad. 2015.

${ }^{44}$ Disponível em http://www.etecsa.cu/internet_conectividad/areas_wifi/. Acesso em 06.mai.2019.
} 


\section{Táticas e Estratégias Cubanas de Conexão: paquete semanal, Snet e Connectify}

O sociólogo Michel Certeau, em seu livro A invenção do cotidiano ${ }^{45}$, analisa a relação entre a macro e micro-estruturas sociais, a partir da distinção entre estratégia e tática. De forma resumida, a estratégia preocupa-se com o estabelecimento e a manutenção do controle dos corpos e das normas em um espaço determinado. A tática, por sua vez, é o conjunto de tentativas de existência e sobrevivência dentro da estratégia pré-concebida. No sentido que apresenta Certeau, identificamos como estratégia, em Cuba, o programa de informatização da sociedade, dentro do contexto de normalização das relações bilaterais entre Estados Unidos e Cuba, formando um cenário distinto que baliza o comportamento e as expectativas da sociedade cubana. Enquanto as táticas são o que cubanos desenvolveram para acelerar o processo de compartilhamento de informação e acesso à conexão. Destacaremos neste trabalho três importantes táticas, desenvolvidas pela sociedade cubana diante da estratégia: paquete, SNET e o uso do aplicativo Connectify.

A partir dessa estratégia que visa a educar tecnologicamente a população cubana insuficiente do ponto de vista técnico para atender a todo o país - nasceram as táticas que vamos descrever a seguir, motivadas pela necessidade de comunicação em rede entre vizinhos, pela necessidade do contato com familiares que vivem fora da Ilha e pela ausência de meios de distribuição de conteúdo, até da produção cultural gerada de forma independente por todo o país.

O paquete semanal é composto por 1 terabite de conteúdo, distribuído às segundasfeiras em todas as regiões da Ilha. Este "pacote semanal” (tradução livre) conta com pastas repletas de novelas, filmes comerciais e de arte, criações audiovisuais independentes locais, músicas, aplicativos, softwares, além de um sistema de publicidade, que aparece inserido em alguns vídeos, em um modelo esteticamente similar ao do YouTube ${ }^{46}$. Quanto ao YouTube, até 2017, quando foi assinado o acordo que permitiu a instalação de servidores do Google na Ilha, a lentidão da conexão local impedia que cubanos subissem vídeos para a plataforma.

\footnotetext{
${ }^{45}$ Michel Certeau, L'invention du quotidien; 1 - Arts de faire, Paris, Gallimard, 1990.

${ }^{46}$ É necessário destacar que a semelhança com o modelo de entrega de anúncios do YouTube se restringe à estética. Afinal, a plataforma de vídeos do Google opera por meio de complexos algoritmos, que determinam a distribuição publicitária e as remunerações consequentes praticamente à revelia de interações humanas: grosso modo, pelo modelo proprietário AdSense, o anunciante seleciona o perfil demográfico de seu público-alvo, designa uma verba de campanha e tem seu conteúdo direcionado a canais afins, proporcionalmente ao investimento. Anunciantes cubanos ainda negociam suas inserções diretamente com os administradores do paquete.
} 
Mas isso não impediu o surgimento de youtubers locais. A diferença entre eles e outros jovens video-blogueiros ao redor do mundo é a distribuição do conteúdo que, no caso cubano, é feita semanalmente, via paquete ${ }^{47}$.

Esse cenário de distribuição via paquete reinou com exclusividade até 2015. A partir de 2016, os youtubers cubanos entram, de fato, na plataforma online, dando à luz a "comunidade Youtube cubana ${ }^{48 ", ~ q u e ~ e m ~} 2017$ celebrou seu primeiro encontro na capital, Havana. Os temas trazidos por esses jovens - muitos já convertidos em celebridades locais são variados: Emma Style, por exemplo, faz tutoriais de maquiagem, dá dicas a estrangeiros para alugar casas em Havana e divide dramas pessoais, como a depressão após uma decepção amorosa e o reatamento da relação com o ex-namorado; Dina Stars canta e conta experiências pessoais, como seu primeiro caso com um estrangeiro ou uma tentativa de estupro que sofreu no bairro onde vive; Adriano "Comepizza Online", faz listas sobre a vida em Havana ou de curiosidades sobre ele mesmo ${ }^{49}$; um dos mais profissionais parece ser o de Camallerys Vlog, que fala sobre turismo, cotidiano e curiosidades da Ilha, a partir de fotos e vídeos de ótima qualidade $^{50}$. O jovem tem uma página própria entitulada Camallerys Travels ${ }^{51}$, onde vende pacotes turísticos para Havana e dá dicas de viagens pela Ilha, inclusive de passeios de luxo. Ou seja, os youtubers cubanos aprenderam a forma, apropriaram-se dela e encontraram espaços de circulação off-line para seus produtos, enquanto o YouTube de fato ainda não era acessível.

Pouco se sabe sobre a origem exata do paquete, mas a prática surgiu como uma gentileza: era comum que quem tivesse acesso à internet descarregasse vídeos, programas, filmes e músicas e disponibilizasse esse conteúdo nos computadores dos centros de trabalho, para serem recuperados com pen-drives por quem se interessasse. A boa-fé virou negócio quando alguém percebeu seu potencial lucrativo e transformou o compartilhamento em serviço. Hoje, grandes estruturas hierarquizadas administram el paquete, cuja existência é conhecida pela esmagadora maioria da população cubana.

A grande diferença da prática entre colegas de trabalho e o que se tornou o paquete é o

\footnotetext{
${ }^{47}$ Surgenen Cuba los “youtubers offline”. Disponível em: <https://progresosemanal.us/20181214/surgen-encuba-los-youtubers-offline/>. Acesso em: 13.maio.2019.

48 AFPES. "Youtubers" cubanos, con poca internet pero con mucho que contar. [s.l.: s.n., s.d.]. Disponível em: <https://www.youtube.com/watch?v=yNRMGBy9xW0>. Acesso em: 13.maio.2019.

${ }^{49}$ Disponível em: https://www.youtube.com/channel/UCDVj1LyOCJOma3R81PZGwaw acesso em: 13.maio.2019.

${ }^{50}$ Disponível em: https://www.youtube.com/channel/UCh7LPHafeQH85zLxOCiFGAQ acesso em: 13.maio.2019.

${ }^{51}$ Disponível em: http://camallerys.com/ acesso em: 13.maio.2019.
} 
download em larga escala. Acredita-se que ele seja feito ilegalmente a partir de centros de trabalho do Estado. Esta denúncia apareceu seguidas vezes em entrevistas formais e informais realizadas durante nosso estudo de campo em Havana, em setembro de 2016. E parece bastante verossímil, já que seria necessária uma qualidade de conexão muito superior à disponível para a população em geral para baixar o volume de conteúdo que é disponibilizado a cada semana.

O escritor e ensaísta Víctor Fowler, durante atividade que discutia a estrutura e os efeitos do paquete, na Associação cubana Hermanos Saíz, classificou a tática de um dos eventos culturais mais importantes que o país viveu nas últimas cinco décadas e completou: "o paquete nos fala de desejos, de redes alternativas, de sujeitos com atitude, autonomia, de consumidores e de carências na oferta ${ }^{52 \%}$.

A estrutura do paquete gerou uma versão offline de um fenômeno já comum em países mais conectados: diferentes padrões de consumo cultural em um mesmo lar. Se, antes do paquete, toda a família assistia a um mesmo programa na televisão ou ouvia uma mesma emissão da rádio estatal, depois dele, o consumo se pulverizou e se individualizou. "Lá em casa, cada membro da família corresponde a um HD”, comentou o professor de Relações Internacionais Jorge Mario Sánchez Egozcue, em entrevista concedida em 2015. Essa individualização do consumo é possível porque, além de disponibilizar uma versão com conteúdo semanal fechado, os distribuidores do paquete também aceitam pedidos avulsos de download. Ou seja, os vendedores de conteúdo oferecem um serviço on demand, que funciona em diversos pontos dos bairros. Os pedidos, segundo Egozcue, vão de novelas brasileiras a filmes de arte. "Minha sogra tem milhares de episódios de novelas, meu filho estuda cinema e consegue grandes raridades com o nosso contato do paquete". O funcionamento e o volume semanal de produtos nos permitem traçar paralelos não só com o YouTube - pela maneira como propicia a ascensão de anônimos à fama- mas também com serviços como Netflix, por seu caráter à la carte.

Essa espécie de sociedade anônima autogerida ficou tão popular que obrigou o poder público a disputar diretamente o interesse da população. No início de 2017, o governo criou um concorrente oficial para o paquete: o Mi Mochila ${ }^{53}$, que disponibiliza a produção cultural

\footnotetext{
52،“el paquete nos habla de deseos, de redes alternativas, de sujetos con agencia, autonomía, de consumidores, de carencias en la oferta". LUCHATUYUCATAINO. El "paquete" semanal cubano a debate. Disponível em: <https://observatoriocriticocuba.org/2014/11/28/el-paquete-semanal-cubano-a-debate/>. Acesso em: 13 maio 2019.

${ }^{53}$ Minha Mochila, em tradução livre.
} 
oficial cubana, tanto audiovisual quanto escrita, além de aplicativos desenvolvidos em Cuba. Poucas semanas após a morte de Fidel Castro, Mi Mochila preparou a distribuição de um especial em homenagem ao principal líder da Revolução.

Em matéria para o site oficial Cubadebate, o jornalista José Raúl Concepción, que produziu uma tese sobre o paquete pela Universidad de La Habana ${ }^{54}$, define a invenção cubana como "uma resposta espontânea diante da carência de oferta estatal, uma via para satisfazer a avidez por informação" 55 (cf. RAÚL CONCEPCIÓN, tradução nossa). Na mesma reportagem, o ex-ministro da cultura Abel Prieto fez defesa do paquete e da tolerância do governo diante dessa tática: "O paquete é o resultado da capacidade inventiva do cubano diante das limitações de acesso à internet, da ausência de televisão a cabo e de outras opções que existem internacionalmente para a difusão de conteúdo cultural ${ }^{56, " ~(i d e m) . ~ P a r a ~}$ Concepción, o paquete é produto da história econômica cubana:

A entrada em Cuba de novas tecnologias coincidiu com a profunda crise econômica da década de 1990. A produção e distribuição nacionais decaíram ao mesmo tempo em que surgiam alternativas para descentralizar a circulação de conteúdo e se naturalizou o mercado negro[sic] como provedor de todo tipo de mercadoria. O paquete não é um produto isolado. Ele pertence a um fenômeno mais abrangente: o consumo audiovisual informal, arraigado em Cuba há mais de duas décadas. Sua origem remonta aos "bancos de filmes" [videolocadoras] que alugavam filmes em formato VHS dos anos 1990 até o início do século. A evolução tecnológica passou para o DVD e o VHS foi substituído por um suporte mais prático $^{57^{3}}$.

Concepción elaborou o organograma a seguir para descrever a organização do grupo: os provedores descarregam o conteúdo e o vendem às matrizes; essas, geralmente localizadas em Havana, organizam os arquivos em pastas temáticas; os distribuidores de primeira mão, em contato direto com as matrizes são os responsáveis por garantir a chegada do conteúdo em seus territórios, um serviço levado a cabo, via de regra, por motoristas de ônibus

\footnotetext{
${ }^{54} \mathrm{La}$ cultura empaquetada: análisis del consumo audiovisual informal del paquete semanal en un grupo de jóvenes capitalinos, José Raúl Concepción Llanes, Universidad de La Habana, 2015.

55 "El paquete es una respuesta espontánea ante las carencias de la oferta estatal, una vía para satisfacer la avidez de información."

${ }^{56} \mathrm{El}$ paquete semanal es el resultado de la capacidad inventiva del cubano ante las limitaciones de acceso a internet, la ausencia de televisión por cable y de otras opciones que existen a nivel internacional para la difusión de mensajes culturales" idem.

${ }^{57} \mathrm{La}$ entrada en Cuba de las nuevas tecnologías coincidió con la profunda crisis económica de la década de 1990. La producción y distribución nacional de audiovisuales decayó al mismo tiempo que surgieron alternativas para descentralizar la circulación de contenidos y se naturalizó el mercado negro como proveedor de todo tipo de artículos. El paquete semanal no es producto aislado, sino que pertenece a un fenómeno más abarcador: el consumo audiovisual informal, arraigado en Cuba desde hace más de dos décadas. Sus inicios se remontan a los "bancos" de películas en formato VHS que rentaban filmes desde los años 90's y principios de este siglo. Luego, la evolución tecnológica dio paso al DVD y los casetes VHS fueron desplazados por un soporte más factible. Idem.
} 
interestaduais, chamados de mensageiros; e os pequenos distribuidores, que trabalham diretamente nos bairros, se instalam em pontos de venda ou levam o paquete a domicílio para os consumidores finais

No topo deste organograma está Élio Héctor López que, apesar da posição hierárquica, tem como apelido análogo a uma função intermediária da cadeia produtiva, el transportador. Longe de ser considerado um subversivo, López mantém relações até compassivas com o Estado: concede entrevistas a veículos oficiais de imprensa e até participa de eventos de comunicação, em que fala sobre a inventividade da internet cubana. Ou seja, há uma relação bipartida entre os provedores do paquete e o Estado: por parte do governo, há uma certa tolerância, já que o grupo oferece o serviço numa escala que a administração pública não é capaz de fornecer - não apenas por uma questão logística, mas também porque ele depende da utilização semilegal dos servidores públicos para o download em larga escala. Ao mesmo tempo, o Estado fornece mi mochila como uma forma de mitigar indiretamente o impacto do paquete sem, no entanto, combatê-lo de forma pró-ativa.

Já com a Snet, o governo não é capaz de tecer uma interação tão cordial. Essa rede offline foi criada por jovens estudantes da UCI e da CUJAE que queriam jogar videogames em rede. $\mathrm{O}$ grupo conseguiu inicialmente conectar alguns computadores fisicamente. Mais tarde, passou a ligar um prédio a outro e, logo, estava conectando bairros inteiros da capital.

Em 2017, quase uma década depois da primeira conexão, Havana contava com nove centrais interconectadas pela cidade e administradas pelo grupo, que hoje é mantido por mais de 150 jovens. O serviço possui um aplicativo de mensagens instantâneas offline, redes sociais, microblogging e fóruns, além de oferecer acesso à Wikipédia offline e, claro, a jogos em rede. A versão atualizada do paquete semanal também está sempre disponível via Snet e, como no paquete, propaganda política e pornografia são proibidas, sob risco de sanções dentro da comunidade. O professor Hamlet López, pesquisador do centro Juan Marinello, define a Snet como "uma rede informática comunitária”, que nasce como

(...) uma resposta autogestionada de alguns setores da sociedade (com capacidade e recurso para isso) à contradição entre a lentidão do desenvolvimento estatal de redes públicas de dados para os cidadãos ea imposibilidade legal para a população estabelecer de maneira autônoma redes de computadores que ofereçam serviços e a facilidade das tecnologias digitais para propiciar e facilitar o trabalho em rede ${ }^{58}$. (LÓPEZ, 2018 p. 89, tradução nossa)

\footnotetext{
58 “(...) una respuesta auto gestionada desde algunos sectores de la sociedad (con la capacidad y los recursos para ello) a la contradicción entre la lentitud en el despliegue de las redes públicas de datos para los ciudadanos por parte de las instituciones estatales, la imposibilidad legal para la población de establecer de manera
} 
Difíceis de encontrar, os gerentes de cada um dos nove pilares de Havana são receosos em dar mais informações sobre o funcionamento da Rede, como eles mesmos a denominam. Em 2016, conseguimos já no final da nossa viagem, uma conversa com três deles, em um parque próximo à celebre sorveteria Coppelia, na capital. Chegamos por meio de um professor da Universidad de la Habana que estava em contato com a equipe e fomos rapidamente atendidos para um primeiro encontro, mas a entrevista formal com mais de um deles ou a visita a um terraço que contasse com o equipamento, nunca aconteceu. Segundo Jordi $^{59}$, responsável por um dos pilares periféricos de Havana, após uma matéria da Associated Press sobre a Snet ${ }^{60}$, o grupo decidiu não conceder mais entrevistas. A matéria, apesar de não trazer duras críticas ao governo, trazia foto e nome de um dos jovens da equipe e, de acordo com ele, construía a imagem de que o grupo estaria construindo uma "rede secreta" e "privada", além de apresentar ao mundo uma tática cubana para vencer os obstáculos da pouca conexão com a World Wide Web. O texto causou ruído em Cuba e, segundo nossa fonte, levou agentes do governo a visitarem membros da Rede e questionarem o projeto que, até então, era tolerado. O alvoroço também levou a empresa estatal de comunicações, ETECSA, a chamar os garotos para uma conversa amigável, mas nenhuma parceria nasceu do encontro. Um ano depois, o portal CubaDebate, que apesar de oficial, é um pouco mais aberto para cobrir pautas originais e tem um foco importante em tecnologia, preparou uma matéria em duas partes sobre a Snet e seus criadores, mas apenas a primeira foi ao $\operatorname{ar}^{61}$. De acordo com uma fonte nossa, o tema causava discórdia dentro do governo e ficou decidido que o portal não deveria alimentar o debate. A segunda parte da matéria seria publicada com alguns ajustes, mas acabou nunca subindo à página do periódico eletrônico.

A terceira tática de conexão da sociedade para acessar a internet nasceu das mesmas cabeças que criaram a Snet. A princípio, a ideia era simplesmente repartir o custo da conexão para os jogos em rede, mas acabou se tornando um concorrente oriundo da sociedade civil às

autónoma redes de computadoras que ofrezcan servicios y la facilidad de las tecnologías digitales para propiciar y facilitar el trabajo en red."

${ }^{59}$ Para garantir a privacidade de nossas fontes os nomes foram alterados.

${ }^{60}$ Matéria disponibilizada na plataforma da agência Associated Press em janeiro de 2015 e entitulada "Cuban Youth built a secret internet network" (Jóvens cubanos constroem rede secreta de internet). Associated Press. Cuban Youth Built A Secret Internet Network. Business Insider. Disponível em: <https://www.businessinsider.com/cuban-youth-built-a-secret-internet-network-2015-1>. Acesso em: 13 maio 2019.

${ }^{61}$ SNet: La primera comunidad inalámbrica en Cuba | Cubadebate. Disponível em: <http://www.cubadebate.cu/noticias/2016/09/16/snet-la-primera-comunidad-inalambrica-en-cuba-fotosinfografia-y-pdf/\#.XNnV-dhv_IU>. Acesso em: 13 maio 2019. 
altas tarifas cobradas pela ETECSA pela hora de conexão ${ }^{62}$. A tecnologia é baseada em um aplicativo estadunidense para compartilhar redes, conhecido como "Connectify" - um software que transforma um computador pessoal ou um celular, conectado a Internet, em um ponto de acesso Wi-Fi (um Hotspot), a partir do qual é possível compartilhar a conexão com qualquer outro dispositivo ${ }^{63}$. Quem oferece o serviço dispõe, normalmente, de um computador ou um celular com o aplicativo capaz de se conectar às redes de hotéis e cybercafés e redistribuir a conexão através de uma antena improvisada. O redirecionamento é revendido aos usuários. Uma hora individual de um cartão ETECSA pode ser revendida a grupos de até dez pessoas, dependendo da qualidade da antena que capta o sinal.

Para inibir a proliferação do serviço, a polícia cubana faz rondas pelos parques onde o serviço oficial é oferecido e procura pelos redirecionamentos na lista de redes wi-fi disponíveis, na tentativa de identificar quem está revendendo a hora. No caso dos roteadores que ficam em espaços privados, como sacadas, tetos e terraços, a polícia chega após detectar movimentações suspeitas ou receber denúncias de vizinhos - o que é raro, mas pode acontecer.

Em setembro de 2016, depois de muitos percalços, conseguimos entrevistar uma única pessoa que trabalhava com este aplicativo desde o início do mesmo ano. Também sob o acordo de não identificá-lo e não gravá-lo, Alejandro ${ }^{64}$ nos mostrou as instalações em sua própria casa: um emaranhado de fios do quarto até a varanda, onde uma antena pequena, mas potente, intercepta a rede ETECSA de um hotel próximo, no bairro de Havana Velha, e distribui para os clientes. O equipamento permite conectar até 7 telefones, que precisam entrar ao mesmo tempo na rede para usar o mesmo cartão de uma hora da ETECSA, na época, a 3 CUC a hora.

Alejandro explica que além de mais barata, a opção é mais "digna" porque, diferentemente do que ocorre nas cercanias imediatas de hotéis, ninguém corre o risco de ser detectado e expulso de um espaço público por acessar a internet. Essa era uma situação comum em Havana: como os hotéis desfrutavam de conexões superiores à dos parques, era corriqueiro ver as calçadas e lobbies lotados de cubanas e cubanos de todas as idades,

\footnotetext{
${ }^{62}$ Uma hora de conexão para cubanos cadastrados no sistema da ETECSA, o "nauta", custa 1 CUC (moeda artificial cubana de valor paralelo ao dólar). Para a população comum, um valor muito expressivo se considerado o salário médio cubano que varia entre 25 e 30 CUC.

${ }^{63}$ Connectify, ahora gratis y en español para los cubanos Cubanet. Cubanet. Disponível em: $<$ https://www.cubanet.org/noticias/connectify-ahora-gratis-y-en-espanol-para-los-cubanos/>. Acesso em: 13 maio 2019.

${ }^{64}$ Para garantir a privacidade de nossas fontes os nomes foram alterados
} 
tentando conversar com familiares por vídeo, mandando mensagens ou resolvendo burocracias com o laptop, em pé. De acordo com Alejandro, seu serviço evita os "constrangimentos, preconceitos e segregação", frequentes no ambiente wi-fi da cidade.

As mudanças na infraestrutura de rede alteraram visivelmente a paisagem da cidade, $o$ que foi possível observar no decorrer dos anos desta pesquisa, nas diferentes visitas que fizemos a Ilha. Desde 2017, a população local habitual começou a escassear nos arredores dos hotéis. Isso porque os gerentes passaram a vender cartões de conexão exclusivos para a rede hoteleira, bloqueando o sinal para quem estivesse na rua. Em dezembro de 2018, foi a vez dos parques equipados com wi-fi esvaziarem significativamente, depois que a ETECSA deu início ao serviço $3 \mathrm{G}$ pela Ilha, permitindo a compra de quatro diferentes pacotes de $\operatorname{dados}^{65}: 600$ $\mathrm{MB}$, por $7 \mathrm{CUC}$; $1 \mathrm{~GB}$ por $10 \mathrm{CUC}$; $2.5 \mathrm{~GB}$ por $20 \mathrm{CUC}$; ou $4 \mathrm{~GB}$ por $30 \mathrm{CUC}^{66}$. Só nos primeiros 40 dias do serviço, 1,8 milhão de cubanas e cubanos teve acesso ao serviço, que registrou cerca de 45 mil novos clientes por dia $^{67}$. Em 2019, Cuba conta 5,9 milhões de usuários da internet. Antes dos pacotes de dados móveis, $60 \%$ dos usuários acessavam a rede a partir dos seus locais de trabalho.

Acreditamos que, se absorvidas pela estratégia do governo, tais táticas teriam grandes chances de bloquear a invasão ofensiva de empresas de tecnologia e informação, as quais poderíamos classificar como uma super-estratégia global, que ameaça a ordem social, política e econômica estabelecida pela Revolução. Portanto, falamos aqui de três camadas de poder: uma super-estratégia que se impõe global e geopoliticamente a partir do império; uma estratégia local determinada na medida do possível pelo governo revolucionário, mas que se vê obrigada a ser tática frente à super-estratégia, ainda que incida estrategicamente sobre a sociedade cubana, que compõe a terceira camada, apenas tática. Defendemos que uma união entre estas duas camadas inferiores seria capaz de, no mínimo, mitigar o impacto da superestratégia sobre os objetivos (ao menos declarados) de autonomia, soberania e continuidade revolucionária de Cuba.

Baseamos tal acepção na evidência de que, apesar de não reconhecidas nem

\footnotetext{
${ }^{65}$ Servicio de Internet para celulares en Cuba a partir del 6 de diciembre (+Tarifas). CiberCuba. Disponível em: <https://www.cibercuba.com/noticias/2018-12-05-u1-e20037-s27061-partir-6-diciembre-activa-internet-datosmoviles-cuba-tarifas>. Acesso em: 13 maio 2019.

${ }^{66} 1$ CUC é equivalente a 24 pesos cubanos e a US\$ 0.90 .

${ }^{67}$ Dados publicados na conta Twitter de OPSalomón, funcionário do Comitê Central do Partido Comunista de Cuba (PCC), após uma reunião com os executivos da ETECSA, em Havana. Primeros datos sobre Internet móvil en Cuba: Más de 1,8 millones de usuarios en 40 días. Cubadebate. Disponível em: <http://www.cubadebate.cu/noticias/2019/01/15/primeros-datos-sobre-internet-movil-en-cuba-mas-de-18millones-de-usuarios-en-40-dias/>. Acesso em: 14 maio 2019.
} 
fomentadas pelo governo, tais táticas foram capazes de atenuar o problema da desconexão a ponto de retardar a entrada de empresas como o Google na Ilha, forçando a companhia inclusive a abrir frentes de atuação específicas para o contexto cubano, das quais trataremos mais adiante. Essas táticas geraram reações díspares do governo, de desconfiança e monitoramento à tolerância e até imitações, como no caso do paquete, que inspirou um concorrente oficial, que comentaremos mais adiante.

À primeira vista, algumas dessas táticas foram encaradas como possíveis janelas para conflitos políticos dentro do país. Isso porque o governo cubano teme, como afirma, por exemplo, Larry Press na já citada entrevista ao Guardian, que a popularização da internet potencialize a organização da dissidência ou mesmo sua instrumentalização para fins contrarrevolucionários. Muito longe de ser uma paranoia estatal, a desconfiança tem fundamento recente.

Um projeto iniciado em 2010 construiu uma rede social nos moldes do Twitter, que podia ser alimentada por breves mensagens de texto. A rede, batizada Zunzuneo ${ }^{68}$, foi arquitetada por um time de empresários de diversos países que, para evitar a rápida associação com o governo dos Estado Unidos (e talvez também por razões fiscais), usaram uma conta nas Ilhas Caymman, para financiar o desenvolvimento do projeto ${ }^{69}$. A operação foi capitaneada pela USAID (United States Agency for International Development), agência dos EUA conhecida por utilizar a entrega de "ajuda humanitária" como pretexto para operações de sabotagem e mudança de regime.

Eva Gollinger e Jean-Guy Allard definem a USAID como principal "braço financeiro de destestabilização e penetração na "sociedade civil'" do Departamento de Estado, peçachave do aparato de segurança e defesa de Washington e uma espécie de eixo ao redor do qual se articulam uma série de fundações conservadoras de política externa, encarregadas de “organizar financiamento e assessoria estratégica a partidos políticos e organizações sociais que promovem sua agenda em países cujos governos não são alinhados aos interesses estratégicos de Washington”. (ALLARD, GOLLINGER, 2009, p. $52^{70}$, tradução nossa)

\footnotetext{
${ }^{68}$ Zunzun é o nome que se dá ao beija-flor, em Cuba, mas a palavra zunzuneo faz referência a informações rápidas que se espalham rápido, bochicho, fofoca.

${ }^{69}$ ASSOCIATED PRESS. US secretly created "Cuban Twitter" to stir unrest and undermine government | World news | The Guardian. The Guardian. Disponível em: <https:/www.theguardian.com/world/2014/apr/03/uscuban-twitter-zunzuneo-stir-unrest>. Acesso em: 13 fev. 2017.

${ }^{70}$ ALLARD, Jean-Guy, GOLINGER, Eva. USA, NED y CIA: La agressión permanente. Ministério del Poder Popular para la Comunicación y la Información, Caracas, 2009.
} 
O Pentágono se encarrega da parte militar, o Departamento de Estado, da diplomaciae a USAID, das populações civis. A USAID serve para promover os interesses econômicos e estratégicos dos Estados Unidos em quase todo o planeta. Seus departamentos dedicados à transição, reconstrução, gestão de conflitos, desenvolvimento econômico, governabilidadee democracia são as principais vias por meio das quais bilhões de dólares oriundos de Washington são injetados em partidos políticos, ONGs, movimentos estudiantis e sociais que promovem seus interesses pelo mundo. Em qualquer país onde tenha havido um golpe de estado, uma revolução colorida ou uma mudança de regime favorável aos interesses dos Estados Unidos, é possível encontrar a USAID e sua chuva de dólares ${ }^{71}$. (Ibidem, tradução nossa)

O Zunzuneo cubano é mais um entre inúmeros exemplos de tentativa de penetração de Washington na sociedade civil de um país não-alinhado por meio da USAID. Em uma matéria da Associated Press, que teve acesso a documentos vazados e pessoas envolvidas no projeto, “o plano foi o desevolvimento de uma espécie de 'Twitter cubano', usando mensagens de texto de celulares para invadir o restrito controle de informação de Cuba e, assim, estrangular as restrições existentes sobre a internet ${ }^{72}$ " (idem, tradução nossa).

Além deste tipo de tentativa exógena de criar hubs de dissidência a partir da conexão, serviços de internet criados dentro da Ilha, sob a vigilância do governo, também entraram no radar da ingerência norte-americana. Criadores da Snet - uma rede offline que conecta computadores por toda a cidade de Havana - e do paquete - pacote de conteúdo multimídia baixado da internet que é distribuído semanalmente por toda a Ilha - chegaram a ser contactados por grandes empresas, que prometeram equipamentos e assistência.

Mas os responsáveis por esses serviços recusaram a ajuda, receosos de serem associados a atividades contrarrevolucionárias e sofrerem represálias por parte do governo ${ }^{73}$. Afinal, ainda que aos olhos da estratégia de desestabilização do Departamento de Estado, serviços de ampliação da conexão - e consequentemente da "liberdade de expressão", na sua já mencionada concepção liberal - parecessem catalizadores naturais da dissidência, a realidade no território era mais complexa.

Essas comunidades tecnológicas surgiram de maneira orgânica dentro da sociedade

\footnotetext{
${ }^{71}$ El Pentágono se encarga de lo militar, el Departamento de Estado de lo diplomático y la USAID de las poblaciones civiles. La USAID sirve para promover los intereses económicos y estratégicos de Estados Unidos en casi todo el planeta. Sus departamentos dedicados a transición, reconstrucción, gerencia de conflictos, desarrollo económico, gobernabilidad y democracia son los principales viaductos a través de los cuales filtran los miles de millones de dólares que desde Washington envían a los partidos políticos, ONGs, movimientos estudiantiles y sociales que promueven sus intereses en el mundo. En cualquier país donde ha habido un golpe de estado, una revolución de colores o un cambio de régimen favorable a los intereses de Estados Unidos se encuentra la USAID y su lluvia de dólares.

72، (...) the project, the plan was to develop a bare-bones "Cuban Twitter," using cellphone text messaging to evade Cuba's strict control of information and its stranglehold restrictions over the internet.“

${ }^{73}$ Essas informações foram cedidas off record em diversas entrevistas que aconteceram em Havana, entre 2016 e 2018.
} 
cubana revolucionária e criaram processos de conexão e compartilhamento profundamente imbuídos do modo de organização desta sociedade: com hierarquias bem-determinadas, regras de convivência e comportamento estritas e um automonitoramento dos tipos de conteúdo disponibilizados.

Um responsável por um destes serviços nos disse, em entrevista concedida sob condição de anonimato: "Não nos interessa que [o governo] nos veja como inimigos. Queremos estar conectados, conversar com familiares, jogar, fazer pesquisas". No caso do paquete, acontece uma rigorosa curadoria, que visa a excluir conteúdo que contenha pornografia e propaganda antigoverno, por exemplo. Os gestores da SNET, por sua vez, realizam uma forte moderação nos fóruns e comunidades da rede. Esse esforço de se enquadrar no esquema pré-estabelecido nesses últimos 60 anos, permitiu que esses grupos fossem tolerados pelo governo e, de alguma maneira, criassem até vinculos com o Estado, como veremos a seguir.

Os dados exatos sobre os distintos usos que enumeramos aqui - oficiais ou não - ainda são desconhecidos. Um dos últimos levantamentos cubanos oficiais aponta que a cada 100 cubanos, 25,7 têm acesso direto à internet e 7,4\% da população possuem computador próprio $^{74}$. Mas o acesso a bens culturais por meio de compartilhamento, pen-drives e todas essas táticas surgidas da sociedade civil não estão computados nesse recenseamento. Recio Silva não nega o fato de que as estatísticas oficiais comprovam que Cuba está quantitativamente aquém da média de conectividade global. Ela pondera, no entanto:

É preciso notar que esses números não expressam de maneira ampla as formas como a sociedade cubana absorve os avanços tecnológicos no campo da infocomunicação (...) a desconexão física não causa necessariamente a desconexão cultural, muito menos na sociedade cubana, que absorve muitas vezes de maneira osmótica as mais diversas redes que a circundam, em suas múltiplas fronteiras subjetivas e materiais ${ }^{75}$. (RECIO SILVA, 2013, p.5. Tradução nossa.)

É comum que pesquisadores usem o tamanho da infraestrutura como parâmetro de medição do grau de conectividade. O que chamamos "penetração da rede" (KELLERMAN, 2004) - a amplitude da infraestrutura em extensão de cabos - serve de fato como indicador, mas a ação dos indivíduos também deve entrar nessa conta, se procuramos analisar o impacto social, cultural e econômico destas novas tecnologias no corpo da sociedade. Mesmo

\footnotetext{
${ }^{74}$ Dados ONEI, 2013 e UIT 2012, elaboração RECIO SILVA, 2013, p. 5.

75، hay que anotar que estas cifras no expresan en toda su amplitud las formas en que la sociedad cubana ha podido absorber (o no) los avances tecnológicos de infocomunicación. (...) la desconexión física no es causa forzada de la desconexión cultural, tampoco en la sociedad cubana que de muchas maneras es osmótica en relación con las más diversas redes que la circundan, en sus múltiples fronteras subjetivas y materiales."
} 
pesquisadores cubanos têm se concentrado na problemática do "acesso", como uma questão prioritária $^{76}$. Mas, como demonstram RECIO SILVA ou o sociólogo francês Fabien Granjon, que estudou os usos das novas tecnologias pelas classes populares francesas, estar online não é a única forma possível de conexão:

\begin{abstract}
Que todo mundo disponha de um computador e de uma conexão não garantiria em nada a existência de um sistema igualitário. Acreditar nisso seria ignorar a disparidade existente na distribuição das capacidades sociais, culturais e técnicas no seio das classes sociais. Faz-se importante então, a distinção, de um lado, das condições de possibilidades materiais de acesso à informática conectada; e de outro, as possibilidades econômicas, sociais e culturais, que possam derivar de um uso da informática conectada e assim, efetivar essas virtudes ${ }^{77}$. (GRANJON, 2011, p.68, tradução nossa)
\end{abstract}

Ou seja, seria leviano ler o fenômeno da internet em Cuba a partir de um dado subjetivo, ideologicamente carregado, como a "liberdade individual de expressão"; ou de um dado objetivo, mas demasiado reducionista, como a extensão física de sua infraestrutura de rede. Esses indicadores exógenos, importados de países cuja história da internet é calcada numa lógica comercial liberal, não oferecem ferramentas capazes de apreender a complexidade da realidade cubana. Confiá-los a árdua missão de ler realidades tão díspares acaba por gerar anacronismos, não apenas em Cuba, mas em outros países, cuja história político-econômica não é ancorada nos preceitos do liberalismo. Apesar das vastas diferenças históricas e culturais que carregam, Estados como Cuba, China e Coreia do Norte são frequentemente equalizados pelo establishment liberal na vala comum do autoritarismo político $^{78}$. E parte dessa definição passa pelo controle governamental sobre a internet - ainda que hoje restem poucas ilusões sobre os impactos do controle corporativo que acomete a rede nos chamados Estados liberais. A censura exercida pelos antigos países comunistas é contrastada ao pluralismo cosmético sustentado pelas grandes potências ocidentais.

Cuba, apresentada à margem da "liberdade", serve a seus detratores como ferramenta comparativa ideológica binária entre o "bem liberal", em que a censura fica a cargo do poder econômico; e o "mal autoritário", quando o Estado se encarrega da censura. Ao analisar o cenário no campo, pode-se verificar muito mais nuances do que esse discurso maniqueísta é

\footnotetext{
${ }^{76}$ RECIO SILVA, 2013.

77، "Que tout le monde dispose d'un ordinateur et d'une connexion n'assurerait pourtant en rien l'existence d'un régime d'avantages de type égalitaire. Le croire, c'est faire l'impasse sur la disparité dans la distribution des capabilités sociales culturelles et techniques au sein des classes sociales. Il est donc essentiel de bien distinguer, d'une part, les conditions de possibilité matérielle d'accès à l'informatique connectée, d'autre part, les potentialités économiques, sociales et culturelles offertes par un usage de l'informatique connectée, enfin, les accomplissements effectifs de ces virtualités.“

78 Os 10 países que mais censuram - Committee to Protect Journalists. Disponível em: <https://cpj.org/pt/2015/04/os-10-paises-que-mais-censuram.php〉. Acesso em: 13 maio 2019.
} 
capaz de captar.

A carência infraestrutural da rede em Cuba não implica necessariamente que a população esteja mal-informada ou alijada de bens culturais (filmes, séries, músicas, vídeos em geral) e informações (livros, cursos de idiomas, wikipedia). Os dispositivos táticos que avaliamos mostram que, apesar do caminho tortuoso para aceder a tais produtos, a sociedade cubana consegue se manter atualizada culturalmente.

A baixa qualidade da conexão direta ao wi-fi ainda restringe o uso que os cubanos fazem da internet online em sites de entretenimento, aplicativos de mensagens instantâneas, troca de fotos e chats com parentes no exterior. Mas todo um ambiente paradoxal de "conexão offline”, que não pode ser ignorado por conta de sua importância sociológica, fica fora desta equação: uma estrutura de distribuição ultrarrápida, com difusão de conteúdo de maneira maciça, periódica, disponível em versão standard ou on demand, como vimos na estrutura do paquete; a criação de redes offline que servem a um objetivo social, com regras e respeito à ordem ética e moral vigente, como no caso da Snet; ou ainda a popularização dos preços de conexão por meio do roubo de rede a partir do aplicativo Connectify: tudo isso redesenha a paisagem de uso das TIC em Cuba e precisa ser levado em consideração. São as nuances dessa série de relações dos cubanos com a internet, lidas dentro de seus contextos social, econômico e político, que nos permitem avaliar o impacto local das novas tecnologias, um impacto que independe dos números concretos dos informes da ONU ou da "lista negra" da ONG francesa RSF (Repórteres sem Fronteiras), que coloca Cuba como "inimiga" da internet $^{79}$.

Uma vez que constatamos todo um universo de circulação de informação, compartilhamento e busca de conteúdo com origem na world wide web, ousaríamos ainda chamar esse fenômeno de desconexão?

Colocamos esta pergunta, visto que o argumento ideológico central para a liberdade de atuação dos grandes conglomerados informáticos estadunidenses - particularmente, o Google - em Cuba se baseia no discurso de que é necessário "conectar o povo cubano", até hoje alijado do acesso à rede. Nem tanto ao céu, nem tanto à terra. Cuba não é tão desconectada quanto indicam as estatísticas oficiais e o Google é muito mais do que um mecanismo de busca ou uma plataforma de promoção do acesso à internet.

\footnotetext{
79 Repórteres Sem Fronteiras atualiza lista de inimigos da Internet. Rede de Jornalistas Internacionais. Disponível em: <https://ijnet.org/pt-br/story/rep\%C3\%B3rteres-sem-fronteiras-atualiza-lista-de-inimigos-dainternet>. Acesso em: 13 maio 2019.
} 


\section{A Entrada do Google em Cuba: histórico, análise e perspectivas}

A aproximação entre Estados Unidos e Cuba foi brecada em muitos aspectos depois da eleição do republicano Donald Trump, em 2016. Durante a administração Barack Obama, Washington realizou o maior esforço em 60 anos para que as relações bilaterais se “normalizassem". A reaproximação foi formalizada com discursos de Obama e Raúl Castro, proferidos e televisionados simultaneamente a 17 de dezembro de 2014, fruto de uma operação diplomática sigilosa, que pegou cubanistas de todo o mundo de surpresa. Nas declarações oficiais, Obama reafirmou diversas vezes seu compromisso em respeitar a soberania cubana e encerrar as campanhas de difamação do governo cubano, um dos grandes investimentos dentro das políticas do embargo contra a Ilha. Todo esse processo de reaproximação entre os dois países aconteceu em várias frentes. Enquanto uma campanha era organizada pelo governo Obama para sensibilizar a população estadunidense sobre a ineficácia do embargo ${ }^{80}$, o setor privado estadunidense, capitaneado pelas companhias digitais do Vale do Silício fazia seu próprio esforço de aproximação econômico-cultural. Representantes do Google fizeram sua primeira visita à Ilha em junho de 2014, seis meses antes de Obama e Raúl Castro declararem oficialmente a reaproximação entre seus países. Na época, a visita de empresas estadunidenses à Ilha ainda era proibida, de acordo com as especificações do embargo.

A julgar pela composição da equipe da transnacional que visitou Cuba em 2014, o discurso anti-intervencionista de Obama parecia excluir o setor privado estadunidense. A visita aconteceu depois de uma reunião com o think tank conservador Heritage Foundation, em 2012 e a declaração de Eric Schmidt, CEO da Alphabet, holding do Google, de que Cuba estava no topo da lista de prioridades do Google ${ }^{81}$. Schmidt foi acompanhado de Brett Perlmutter, que pertencia a equipe do Google Ideas (braço geopolítico da companhia, que seria rebatizado de Jigsaw, em 2016) e se tornou mais tarde o responsável do Google para Cuba; Dan Keyserling, que começou sua carreira na campanha presidencial de Hillary Clinton, em 2008, e se juntou ao Google para ser chefe de operações do Jigsaw; e o já citado Jared Cohen, presidente do Jigsaw e ex-conselheiro no Departamento de Estado sob

\footnotetext{
${ }^{80}$ Informações tiradas do debate do Congresso Internacional da LASA, em maio de 2016, em Nova Iorque, Obama's Rapprochemont with Cuba: Influences and Influencers in Changing U.S. Presidente.

${ }^{81}$ SCHMIDT, Eric. Trapped in its history, beautiful Havana recalls the faded grandeur of.... Disponível em: <https://plus.google.com/+EricSchmidt/posts/X8UXDYZEwdu>. Acesso em: 2 ago. 2016.
} 
Condoleezza Rice e Hillary Clinton, responsável pela informatização do ministério e com importante atuação durante a Primavera Árabe (ASSANGE, 2014:21-2). A presença da equipe do então Google Ideas, que prometia, à época, proteger ciberdissidentes de possíveis ataques hackers de governos autoritários, denotava o peso político da visita ${ }^{82}$.

A agenda contou com uma visita à redação do site jornalístico 14 y medio, da jornalista e crítica ferrenha do governo revolucionário, Yoaní Sanchez, além de reuniões com profissionais de tecnologia e uma visita guiada à Universidade de Ciências Informáticas (UCI) de Havana ${ }^{83}$. Um dos objetivos da companhia na Ilha era fazer uma avaliação prévia para o projeto técnico que propunha a instalação de balões ${ }^{84}$ equipados com $w i-f i^{85}$ no céu cubano. Em 20 de agosto de 2014, o navegador Google Chrome foi liberado para Cuba ${ }^{86}$ e, em 26 de novembro do mesmo ano, ainda alguns dias antes da notícia de que os Estados Unidos e Cuba retomariam diálogo, foi a vez dos aplicativos Google Analytics e Google Play $^{87}$. Todos esses serviços estavam inacessíveis na Ilha por conta das regras de exportação expressas no bloqueio ao país.

A repentina atenção da empresa para Cuba despertou alguma desconfiança nos meios jornalísticos oficiais cubanos, que até então, liam a restrição de ferramentas como o Analytics como censura imposta pela transnacional à população da Ilha ${ }^{88}$. Em nota datada de novembro de 2014, o diário digital On Cuba expressou a preocupação com o Google nos seguintes termos:

A abertura desses serviços para Cuba responde ao interesse da companhia de expandir atividades em países que, de acordo com o governo estadunidense, mantêm "regimes restritivos", como já aconteceu com Google Earth, Picasa e Chrome, que começaram a funcionar no Irã em 2011 e na Síria em 2012 [período que ficou conhecido como Primavera

\footnotetext{
${ }^{82}$ https://thefwa.com/cases/google-ideas

${ }^{83}$ 14YMEDIO. Presidente ejecutivo de Google visita Cuba. 14ymedio. Disponível em: <https://www.14ymedio.com/nacional/Presidente-Google-visita-oficial-Cuba_0_1586841303.html>. Acesso em: 19 mar. 2019.

${ }^{84} \mathrm{O}$ projeto existe há cerca de oito anos com o objetivo de conectar áreas desconectadas do Globo, com foco no sul global e, há um ano, Google e a empresa queniana Telkom Kenya assinaram um acordo para que os loons funcionassem de maneira comercial na país. AL JAZEERA ENGLISH. Is Big Tech colonising the internet? | All Hail The Algorithm, 10 jul. $2019 . \quad$ Disponível $<$ https://www.youtube.com/watch?reload=9\&v=_fC7acShZkg\&feature=youtu.be >. Acesso em: 18 jul. 2019 ${ }^{85}$ https://loon.co/

${ }^{86}$ Disponible para Cuba, de forma oficial, Google Chrome. Disponível em: <https://gutl.jovenclub.cu/disponiblepara-cuba-google-chrome/>. Acesso em: 20 mar. 2019.

${ }^{87}$ Apps gratuitas de Google Play y Analytics disponibles para Cuba. Disponível em: $<$ https://oncubanews.com/tendencias/tecnologia/apps-gratuitas-de-google-play-y-analytics-disponibles-paracuba/>. Acesso em: 20 mar. 2019.

${ }^{88}$ Escandalosa censura de Google a Cuba: Medios y blogueros de la Isla no pueden acceder a estadísticas. Cubadebate. Disponível em: <http://www.cubadebate.cu/noticias/2012/06/19/escandalosa-censura-de-google-acuba-medios-y-blogueros-de-la-isla-no-pueden-acceder-a-estadisticas/>. Acesso em: 22 fev. 2018.
} 
Árabe]. ${ }^{89}$

Mas o primeiro artigo que alertou a Ilha sobre a ligação entre o Google e o Departamento de Estado foi publicado pelo jornalista da imprensa oficial cubana Iroel Sanchez no dia $1^{\circ}$ de julho de 2014 , logo depois da visita do corpo diretivo da transnacional. Nele, Sanchez explica quem é Jared Cohen, sua relação com o Departamento de Estado a partir dos vazamentos publicados pelo Wikileaks e critica a cobertura midiática do caso:

[...] Cohen e dois dos seus acompanhantes visitaram a colaboradora da embaixada estadunidense mais mencionada nas conversas diplomáticas secretas publicadas pelo Wikileaks, Yoani Sánchez. Os visitantes do Google se abstiveram de falar em Cuba com a imprensa, tanto nacional como estrangeira. Ao que parece, para garantir a primazia da informação à senhora Sánchez. [...] Os meios de comunicação também não falaram que Eric Schmidt é presidente do grupo que coordena a New America Fundation ${ }^{90}$, principal beneficiária dos fundos da USAID para programas "pró-democracia" em Cuba e encarregada do projeto Commotion que o New York Times revelou como destinado a Cuba. A New America Foundation recebeu só em setembro de 2013, 4,3 milhões de dólares da USAID para desenvolver projetos em Cuba durante três anos ${ }^{91}$.

Depois de uma nova visita do Google à Ilha no início de 2015, foi a vez do engenheiro

Karel Pérez Alejo, desenvolvedor de rede e professor universitário, alertar, durante entrevista, para a "ingenuidade" de Cuba em relação ao Google:

[...] primeiro, não foi o Google que veio [a Cuba]; foi o Google Ideas, e veio pela segunda vez. O Google Ideas, que está muito próximo ao Departamento de Estado e, em particular, da Hillary Clinton. [...] Por que eu faço essa distinção entre o Google e o Google Ideas? Porque nessas duas visitas não houve ninguém com um enfoque tecnológico, e ao que parece pelo que se soube das conversas que aconteceram, não se falou em tecnologia, mas em política tecnológica. [...] Não podemos ser ingênuos, principalmente em relação à visita do Google Ideas. Seria muito diferente se no lugar de seus diretores, viessem os diretores do Google Glass, ou do Google Maps. Mas, justamente, não foi a ala técnica do Google quem veio, mas a ala política, que é uma extensão do Departamento de Estado. Se fosse o Yahoo Ideas seria o mesmo critério, porque não são questões técnicas as que interessam a eles. Repito: não se pode ser ingênuo ${ }^{92}$.

\footnotetext{
89 "La apertura de estos servicios a Cuba responde al interés de la compañía en expandirse a países que, según el gobierno estadounidense, mantienen "regímenes restrictivos", como ya hicieron con Google Earth, Picasa y Chrome puestos en marcha en Irán en 2011, y Siria en 2012." Idem. Tradução nossa.

${ }^{90}$ Disponível em: https://www.newamerica.org/our-people/eric-schmidt/ acesso em: 20 mar. 2019.

${ }^{91}$ [...] Cohen y dos de sus acompañantes visitaron en Cuba a la colaboradora de la embajada estadounidense más mencionada en los cables diplomáticos secretos filtrados por Wikileaks, Yoani Sánchez. Los visitantes de Google se abstuvieron de hablaren Cuba con la prensa, tanto nacional como extranjera. Al parecer, esta postura tuvo la intención de regalar la primicia informativa a la señora Sánchez. [...] Tampoco los medios han dicho que Eric Schmidt es chairman de la Junta de la New America Fundation, principal beneficiaria de los fondos de USAID para los programas "prodemocracia" en Cuba, encargada del proyecto Commotion que el New York Times reveló como destinado a nuestro país. New America Foundation recibió en septiembre de 2013 4,3millones de dólares de la USAID para desarrollar proyectos en Cuba durante tres años. El maletín que Google trajo a Cuba | La pupila insomne. Disponível em: <https://lapupilainsomne.wordpress.com/2014/07/01/elmaletin-que-google-trajo-a-cuba/>. Acesso em: 20 mar. 2019.

92 “[...] primero, que no vino Google; vino Google Ideas, y vino por segunda vez. Google Ideas, que está muy cercano al Departamento de Estado, y en particular a Hillary Clinton [...] ¿ Porqué hago la distinción entre Google y Google Ideas? Porque en esas dos visitas al país no ha venido nadie con un enfoque tecnológico, y al
} 
De acordo com Iroel Sánchez, durante a visita março de 2015, Eric Schimit, Brett Perlmutter, Jared Cohen e Scott Carpenter (diretor adjunto do Google Ideas, que diferentemente dos demais, viajava pela primeira vez à Ilha) estiveram novamente na UCI para conversar com professores e alunos; mas também foram à Universidad Tecnológica de La Habana (CUJAE) e também ao Joven $\mathrm{Club}^{93}$.

Assim como a visita anterior do Google, que precedeu o anúncio da retomada das relações bilaterais, esta visita de março de 2015 preparava terreno para outro momento histórico: a reabertura das embaixadas cubana e estadunidense nos respectivos países, que ocorreu no segundo semestre de 2015, gerando um fluxo de trocas entre diplomatas, artistas e políticos. Foi esta profusão inédita de intercâmbios que possibilitou o primeiro projeto concreto do Google na Ilha, a abertura de uma espécie de "espaço Google", no Estúdio Kcho Museo Orgánico Romerillo ${ }^{94}$. O espaço do artista plástico Alex Leyva, conhecido como Kcho, leva o nome do bairro popular de Havana em que está situado, Romerillo, e tem como objetivo declarado popularizar o acesso à arte na comunidade local. Em 2015, o artista quis compartilhar a internet ADSL à qual tinha direito ${ }^{95}$, de maneira livre e gratuita com a população do bairro. Com o tempo, um acordo com a empresa estatal de comunicação garantiu a expansão do serviço oferecido pelo artista através de um spotwi-fi, o primeiro gratuito de toda Cuba. O Google não faz parte do nascimento do espaço, mas ainda assim, desde março de 2016, tem seu logotipo destacado ao lado do nome do museu.

Existe uma anedota (não se sabe se verdadeira ou não) em torno da parceria entre Kcho e Google: o artista, de passagem por Washington para a reabertura da embaixada cubana nos Estados Unidos, teria encontrado por acaso com Brett Perlmutter - que acabara de assumir o comando da missão do Google para Cuba - e brincado sobre a dificuldade de se

parecer por lo que ha trascendido de las conversaciones que ha habido, no se ha hablado de tecnología sino de política tecnológica. [...] no podemos ser ingenuos, sobretodo en este caso de la visita de Google Ideas. Sería muy diferente si en lugar de sus directivos, hubieran venido los de Google Glass, o los de Google Map. Pero, justamente, no fue el ala técnica de Google quien vino, fue el ala política, que es una extensión del Departamento de Estado. Si fuera con Yahoo Ideas sería el mismo criterio, porque no son cuestiónes técnicas lo que les interesa. Te repito, no se puede ser ingenuo. Google Ideas no es Google". Disponível em: <https://progresosemanal.us/20150326/google-ideas-no-es-google/>. Acesso em: 20 mar. 2019.

${ }^{93}$ INSOMNE, La pupila. Google en Cuba again: ¿Nuevas ideas? Disponível em: $<$ https://lapupilainsomne.wordpress.com/2015/03/13/google-en-cuba-again-nuevas-ideas/>. Acesso em: 20 mar. 2019.

${ }^{94}$ Video do evento no Estúdio Kcho-MOR, disponível em: http://laredcubana.blogspot.com/2016/03/opening-ofgooglekcho-tech-center-much.html acesso em: 16 nov. 2016.

95 Em Cuba, alguns profissionais, como médicos, jornalistas e artistas tinham a possibilidade de ter uma conta ADSL em casa, com um número limitado de horas de conexão por mês. 
conectar ao wi-fi do hotel. "Nem na capital dos Estados Unidos a internet funciona direito", teria dito Kcho. Aproveitando a descontração, o artista teria aberto a discussão sobre a possibilidade de um apoio logístico por parte da transnacional para seu espaço cultural.

Em troca do logo na fachada do Espaço Kcho, a empresa do Vale do Silício doou 100 Google cardboards, ou máscaras de papelão, que, conectadas a um smartphone, podem simular a experiência da realidade virtual; duas câmeras para a realização de transmissões ao vivo pela internet (streaming); 20 telefones Google Nexus - obsoletos, uma vez que naquele momento, a geração seguinte do aparelho, o Google Pixel, já estava em circulação -; e 20 Chromebooks com 100GB de armazenamento na nuvem, ou seja, computadores que só funcionam conectados à internet por não possuírem memória interna. Um "computador com respiração artificial $^{96 "}$, retomando a acertada expressão do jornalista Javier Martín, do diário espanhol El País.

Como podemos avaliar essa doação de aparelhos que não funcionam no contexto cubano ou que funcionam de maneira limitada? Como se explica que uma empresa do porte do Google faça uma doação de estreia em um país com produtos obsoletos? Colocamos essas perguntas à diretora de comunicação do museu, Leysi Rubio, durante uma entrevista concedida em Havana, em 2016. De acordo com Rubio, a doação discreta era apenas uma demonstração das parcerias futuras que a empresa ainda pode realizar com Cuba. Ela fez questão de lembrar que, para o Google, este é um passo importante e muito difícil, já que o embargo financeiro e comercial coloca a empresa em uma batalha jurídica intensa.

Mas enquanto as questões legais não se resolvem, o Google tem um muro inteiro de propaganda 24 horas por dia, 7 dias na semana, em Havana. Ainda que a empresa siga sendo praticamente inexistente do ponto de vista jurídico no país, essa parceria proporcionava, naquele momento, que ela povoasse o imaginário não apenas de quem entra no Estúdio, mas de quem passa pela avenida que ladeia o terreno do espaço. Segundo Rubio, a empresa deve ajudar o país a "tirar blocos do muro do embargo".

A parceria não concretizou o relaxamento do embargo - não apenas porque o aporte infraestrutural foi insuficiente, mas por causa do câmbio geopolítico proporcionado pela eleição de Trump, como veremos adiante. Mesmo assim, consolidou-se na imprensa a ideia de

\footnotetext{
${ }^{96}$ Chromebook, un ordenador con respiración asistida | Tecnología | EL PAÍS. Disponível em: <https://elpais.com/tecnologia/2011/06/22/actualidad/1308733268_850215.html>. Acesso em: 24 fev. 2018.
} 
que o Google estava levando infraestrutura de conexão ao museu ${ }^{97}$, o que não é verdadeiro: apesar de a banda ter sido aumentada depois da parceria, a conexão que era disponibilizada gratuitamente pelo Espaço Kcho era providenciada pela ETECSA.

A partir de 2017, problemas judiciais - incluindo uma dívida importante de Kcho com a ETECSA - tiraram o artista de circulação e o espaço se desarticulou. Na nossa última visita à Ilha, em 2018, o acesso à internet estava sendo cobrado normalmente a partir da compra de cartões nauta; e outras redes pirateavam o sinal vindo do museu, o que deixava toda a conexão muito mais lenta. $\mathrm{O}$ museu estava vazio, com pedaços de obras antigas do lado de fora do barracão do artista. Segundo a guia que nos acompanhou, o espaço estava preparando uma nova exposição para o mês seguinte, mas não foi possível aferir que ela de fato tenha acontecido.

Outras parcerias do Google com a sociedade civil cubana foram acontecendo. No início de 2017, o Google, a Oficina del Historiador de la Habana ${ }^{98}$, o Museu do Bronx e a Fundação Ford lançaram um documentário de curtametragem em 3D sobre a história do poeta e líder independentista cubano José Martí, intitulado Nuestro Martí, na plataforma digital Google Arts\&Culture ${ }^{99}$. Em maio de 2018, o Google participou da Parada LGBTQI, em Havana, organizada pelo Centro Nacional de Educação Sexual de Cuba (Cenesex) com uma extensa faixa com o nome da empresa nas mãos de alguns militantes.

E depois de estar presente no museu, na periferia de Havana; no audiovisual, com o curta sobre Martí e apoiando marchas por direitos humanos na Ilha, o Google mirou a moda, outro bastião da cultura. Em 2018, a empresa assinou toda uma coleção com a marca de roupas Clandestina ${ }^{100}$. A grife cubana existe desde 2015 e foi a primeira a ter um site para vender seus produtos. Em novembro de 2018, eles se uniram para assinar juntos a coleção País en construcción. "O trabalho delas se ajusta muito naturalmente à conexão que estamos tentando estabelecer aqui", disse a chefe de marketing do Google em Cuba, Susanna Kohly Jacobson ${ }^{101}$, funcionária da transnacional desde 2014.

\footnotetext{
${ }^{97}$ Free Internet, Free Cuba: How Easing U.S. Sanctions and a Havana Google Internet Café May Transform Cuba's Telecommunications and Internet Industries | Perspectives | Reed Smith LLP. Disponível em: $<$ https://www.reedsmith.com/en/perspectives/2016/12/free-internet-free-cuba-how-easing-us-sanctions-an>. Acesso em: 21 mar. 2019.

${ }^{98}$ Núcleo de recuperação e defesa do patrimônio histórico de Havana.

${ }^{99}$ Google y la Oficina del Historiador de La Habana presentan un documental sobre José Martí en 3D. Diario de Cuba. Disponível em: <http://www.diariodecuba.com/cuba/1484307923_28101.html>. Acesso em: 10 fev. 2019.

${ }^{100}$ Disponível em: https://clandestina.co/ acesso em: 10 fev.2019.

101“Para nosotros, Clandestina representa lo que es posible hacer en Cuba (...). Nos gusta mucho lo que hacen con el dinosaurio de Chrome y su trabajo se ajusta muy naturalmente a la conexión que tratamos de establecer
} 
Ou seja, que o Google fez até 2018 foi se legitimar a partir de ações culturais. É essa sagacidade na atuação dentro do território que transforma a participação ativa na vida cultural local em ações políticas subjetivas.

Do ponto de vista institucional, o primeiro contrato do Google com Cuba foi assinado em 12 de dezembro de 2016 por Eric Schmidt e Mayra Arevich Marín, presidenta da ETECSA. Brett Perlmutter também estava presente. O acordo possibilitou a instalação de servidores do Google na Ilha, o Google Global Cache, colocado em funcionamento em abril de $2017^{102}$. Os servidores locais aprimoraram a velocidade e a qualidade da conexão, o que melhorou, por exemplo, o acesso da população ao YouTube. Aquele acabou sendo o primeiro e único contrato formal entre uma empresa de tecnologia estadunidense e o Estado cubano. Uma das principais razões para a descontinuidade foi justamente a vitória de Trump, que renovou o discurso de hostilidade a Cuba.

Depois da eleição de Miguel Díaz-Canel ${ }^{103}$, uma importante transição simbólica no governo revolucionário ${ }^{104}$, houve maior abertura no diálogo com empresas estrangeiras. Em 4 de junho de 2018, Eric Schmidt e o ex-senador republicano Jeff Flake fizeram uma visita de 24 horas à Ilha. Na breve passagem, reuniram-se com o novo presidente e os ministros das Relações Exteriores e das Comunicações, Bruno Rodríguez e Jorge Luis Perdomo Di-Lella, respectivamente. Também esteve presente nas reuniões o mais antigo diplomata estadunidense em Cuba, Philip Goldberg ${ }^{105}$. Nessa ocasião, o presidente e a empresa firmaram quatro memorandos de entendimento ${ }^{106}$ assinados também pela Universidad de las Ciencias Informáticas, Infomed, pelo Ministério da Cultura e pela Oficina del Historiador de La Ciudad de La Habana. O conteúdo dos memorandos não veio a público, apesar de

aquí”. GARCÍA, Yeny. 'T-Rex de la desconexión' de Google, mascota de la Cuba que anhela internet. 14ymedio. Disponível em: <https://www.14ymedio.com/nacional/Google-Cuba-internet-ClandestinaModa_0_2549145064.html>. Acesso em: 25 mar. 2019.

${ }^{102}$ Google Global Caché ya está disponible en Cuba. Cubadebate. Disponível em: <http://www.cubadebate.cu/noticias/2017/04/27/google-global-cache-ya-esta-disponible-en-cuba/>. Acesso em: 25 mar. 2019.

${ }^{103}$ Eleito aos 57 anos (jovem para o padrão octogenário da Revolução), Díaz-Canel protagonizou a primeira campanha presidencial por redes sociais da história do país, amparada no paradoxal slogan \#somoscontinuidad.

${ }^{104}$ OLIVEIRA, Vanessa. Cuba: reinvenção ou arranjo burocrático? Disponível em: <https://outraspalavras.net/sem-categoria/cuba-reinvencao-ou-arranjo-burocratico/>. Acesso em: 25 mar. 2019.

${ }^{105}$ U.S. Senator Flake, former Google CEO meet with new Cuban president. Reuters, 2018. Disponível em: <https://www.reuters.com/article/us-cuba-usa-idUSKCN1J0323>. Acesso em: 28 mar. 2019.

${ }^{106} \mathrm{O}$ memorando de entendimento ou MOU (Memorandum of understanding) é um primeiro passo para a formalização de um documento jurídico mais elaborado como um contrato social. Serve para alinhar entre duas ou mais partes os termos e detalhes de um acordo, assim como deixar claro direitos e deveres dos envolvidos. 
especulações principalmente da mídia anticastrista, de que Cuba teria assinado cláusulas se comprometendo com a liberdade de expressão na internet ${ }^{107}$.

Poucos meses depois, em setembro de 2018, Díaz-Canel devolveu a visita acompanhado do chanceler Bruno Rodríguez Parrilla, o Ministro do Comércio Exterior, Rodrigo Malmierca Díaz, e o Ministro das Comunicações, Jorge Luis Perdomo Di-Lella ${ }^{108}$, em Nova York, no escritório do Google. Outras empresas de tecnologia e comunicação também estiveram presentes ${ }^{109}$. Em uma conversa off the record com funcionários dos Ministérios das Relações Exteriores e das Comunicações, em Havana, em dezembro de 2018, nos inteiramos de que um dos pedidos da empresa durante a conversa em Nova York foi o investimento na compra maciça de smartphones - segundo as empresas, devido ao seu potencial "empoderador". A sugestão já havia sido feita em 2015 por Brett Perlmutter, durante um encontro com jornalistas do site $O n C u b a$, desta vez sob um discurso de praticidade e visão de futuro ${ }^{110}$. Em 29 de março de 2019, Google e ETECSA assinaram um novo memorando de entendimento, segundo a nota oficial enviada à imprensa ${ }^{111}$.

\section{Conclusão}

Analisamos o cenário cubano de tecnologias da informação e da comunicação a partir das estratégias e táticas presentes na sociedade cubana, contando suas especificidades e as

\footnotetext{
${ }^{107}$ Google and Cuba close to finalizing agreement to expand internet access on the island. miamiherald. Disponível em: $<$ https://www.miamiherald.com/news/nationworld/world/americas/cuba/article212660549.html>. Acesso em: 28 mar. 2019.

${ }^{108}$ Presidente cubano Díaz-Canel visitas e de de Google en Nueva York. Granma.cu. Disponível em: <http://www.granma.cu/cuba/2018-09-24/cordial-intercambio-del-presidente-cubano-con-representantes-de-lasnuevas-tecnologias-24-09-2018-21-09-55>. Acesso em: 28 mar. 2019.

${ }^{109}$ Estiveram na reunião as empresas: VaynerMedia, Connectify, Mapbox, Virgin Group, AirBnB, Revolution, Twitter, Microsoft, Bloomberg e Cresta

110 "Muita gente nos vê apenas como um buscador, mas somos uma das empresas de maior infraestrutura no mundo e podemos fazer com que a infraestrutura do país cresça. Cuba tem a grande oportunidade de saltar diretamente à telefonia móvel, como estão fazendo os países da África, sem passar por todo o caminho do cabeamento" Empresas norteamericanas exploran oportunidades en Cuba. OnCuba News, 16 jun. 2015. Disponível em: <https://oncubanews.com/cuba/empresas-norteamericanas-exploran-oportunidades-en-cuba/>. Acesso em: 22 jul. 2019

111 “(...) começar a negociação de um posterior acordo de serviço de intercâmbio de tráfego de internet (conhecido tecnicamente como peering), com o objetivo de melhorar a qualidade do acesso aos conteúdos da internet. A intenção de trabalho colocada no Memorando de Entendimento será implementada quando existirem as condições técnicas necessárias. A implementação deste serviço (...) faz parte da estratégia da ETECSA para o desenvolvimento e informatização do país. A este Memorando entre ETECSA e o Google, antecede a sanção e realização do acordo do Google Global Cache, assinado em dezembro de 2016 e inaugurado em abril de 2017, com bons resultados". Nota de prensa conjunta ETECSA-Google para anuncio de firma de Memorándum de $\begin{array}{lllllll}\text { Entendimiento } & 28 & \text { de } & \text { marzo } & \text { del } & 2019 . & \text { Disponível }\end{array}$
} <http://www.etecsa.cu/inicio/nota_de_prensa_conjunta_etecsa_google/>. Acesso em: 29 mar. 2019. 
brechas por onde grandes transnacionais estão traçando suas estratégias. No caso do Google, ainda que a empresa não tenha ainda realizado seus projetos práticos de conectividade, ela surpreendeu ao desenvolver uma estratégia de penetração cultural na Ilha, um approach inteligente, que seguiu muito a política de soft power desenvolvida por Obama: inteligente, descolada, colorida e jovem, este último sendo um atributo dos mais atrativos para um território cujo governo permanece há seis décadas.

Para além da contradição presente na postura do governo cubano - ainda que se compreenda a necessidade que o país tem de acelerar sua inserção no mercado global, capacitando sua população para que ela siga competitiva e colaborando com avanços tecnológicos pelo mundo, como tem sido há muito - , faz-se cada vez mais necessário analisar os efeitos que essas empresas terão a médio e longo prazo não só na economia e na política cubanas como nas do sul-global geral, com históricos semelhantes de exploração e subdesenvolvimento tecnológico - além, claro, das possíveis influências e modulações dos cenários que se estabelecerão politicamente num futuro próximo.

\section{Bibliografia}

\section{Livros}

ALLARD, Jean-Guy, GOLINGER, Eva. USA, NED y CIA: La agressión permanente. Ministério del Poder Popular para la Comunicación y la Información, Caracas, 2009.

ARON, Raymond. Essai sur les libertés. Hachettes, Paris, 1965.

ASSANGE, Julian. When Google Met Wikileaks. 1 edição ed. [S.1.]: OR Books, 2014. DE CERTEAU, Michel. L'invention du quotidien; 1 - Arts de faire, Paris, Gallimard, 1990.

HOFFMANN, Bert. The politics of internet in third world development: challenges in contrasting regimes with case studies of Costa Rica and Cuba, University of California, San Diego, 2004.

SWEIG, Julia. Cuba: What Everyone Needs to Know, Oxford University Press, New York, 2008.

\section{Artigos acadêmicos}


ARSÈNE, Séverine. De l'autocensure aux mobilisations, About autocensorship and mobilizations. Revue française de science politique, v. 61, n. 5, p. 893-915, 14 out. 2011.

SILVA, Milena Recio. La hora de los desconectados. Crítica y Emancipación, n. 11, 2013. Disponível em:

$<$ http://www.biblioteca.clacso.edu.ar/ojs/index.php/critica/article/download/30/31 >. Acesso em: 26 out. 2016.

URRA GONZÁLEZ, Pedro. Information systems in health: a conversation with Pedro Urra González. Salud Colectiva, v. 7, n. 1, p. 99-111, 2011.

LÓPEZ GARCÍA, Hamlet. Cultura digital participativa y software libre en Cuba. Revista SWLX, n. 3 ano 1, p. 16-23, 2014. Disponível em: < https://gutl.jovenclub.cu/wp-content/ftp/ftpgutl/docs/revistas/swl-x/swlx3.pdf $>$ Acesso em: 4 mar. 2016.

LAÍN ESCANDELL, B. Bienes comunes, nuevos cercamientos y economía política popular. Política y Sociedad, v. 52, n. 1, 27 abr. 2015.

RICHERI, Guseppe. L'Internet en Chine, entre État et opinion publique, Les Enjeux de l'information et de la communication, vol. 19/1, no. 1, 2018, pp. 21-33.

HABEL, Janette. Raúl Castro a la hora de las decisiones, América Latina Hoy, 52, 2009, Ediciones Universidad de Salamanca, p. 99-100. http://revistas.usal.es/index.php/11302887/article/viewFile/5677/5712, Acesso em 05. Mai.2019.

\section{O Panorama da Internet em Cuba e uma Análise da Chegada do Google na Ilha}

\section{Resumo}

Este artigo tem como objetivo discutir o fenômeno da desconexão em Cuba (RECIO, 2013) a partir da apresentação do cenário de desenvolvimento das tecnologias na Ilha desde o início da Revolução de 1959 (ALFONSO, 1993) até o início de 2019. Abordamos a concepção de tecnologias propriamente cubanas (PRESS, 2011; URRA, 2011), a absorção das "novas tecnologias" pela sociedade, além de apresentar uma série de táticas cubanas que foram desenvolvidas na tentativa de superar a precariedade da infraestrutura de rede no território, driblando as limitações materiais geradas pelo embargo imposto contra a Ilha pelos Estados Unidos desde o início dos anos 1960 (BRITO, 2019). Apresentamos assim, a evolução dos setores formal e informal de telecomunicações em Cuba durante a chamada Atualização do Socialismo Cubano (HABEL, 2009) e do processo de restabelecimento das relações bilaterais entre Cuba e Estados Unidos, com especial foco na polêmica aproximação do Google, considerado neste artigo um ator geopolítico dos Estados Unidos, devido as suas relações com o Departamento de Estado dos EUA durante a gestão de Barack Obama (ASSANGE, 2014). Encerramos com uma linha do tempo das ações da empresa em Cuba e uma análise de sua atuação durante os primeiros anos dos governos de Miguel Díaz-Canel e Donald Trump.

Palavras-chave: tecnologia, internet, cuba, google

\section{Internet Iandscape in Cuba and the Arrival of Google in the Island}

\footnotetext{
Abstract

The present article discusses the phenomena of disconnection in Cuba (RECIO, 2013), based on the analysis of the history of communications in the Island, from the 1959 Revolution (ALFONSO, 1993) until early 2019. We list Cuban-developed internet technologies (PRESS, 2011; URRA, 2011), the absortion of external technologies by the society, and the tactics designed by the population to try and overcome their lack of infrastructure, by
} 
tackling material limitations imposed by the economic embargo enforced by the U.S. since the early 1960s (BRITO, 2019). We then discuss the evolution of formal and informal telecommunications in Cuba during the period known as the "Actualización del Socialismo Cubano" (Actualization of Cuban Socialism, HABEL, 2009) and the process of re-establishing diplomatic relations with the United States, with a special focus on the role played by Google - considered herein to be not only a corporation but an American geopolitical actor, due to its close ties with the State Department throughout the Obama administration. We end up by establishing a time line of Google's actions towards Cuba and analyzing its actions in the first few years under Donald Trump and Miguel Díaz-Canel.

Keywords: technology, internet, cuba, google

\section{El Panorama del Internet en Cuba y um Analisis de la llegada del Google em la Isla}

\section{Resumen}

Este artículo tiene por objectivo discutir el fenómeno de la desconexión en Cuba (RECIO, 2013) a partir de una presentación del escenario del desarrollo de las tecnologías en la Isla desde los principios de la Revolución, en 1959 (ALFONSO, 1993) hasta el principio del año de 2019. Abordamos la creación de tecnologías propiamente cubanas (PRESS, 2011; URRA, 2011), la absorción de las "nuevas tecnologías" por parte de la sociedad, además de presentar una serie de tácticas cubanas desarrolladas para superar la precariedad de la infraestructura de red en el territorio, huyendo de las limitaciones materiales generadas por el bloqueo impuesto por los Estados Unidos desde el principio de los años 1960 (BRITO, 2019). Así, presentamos la evolución de los sectores formales e informales de las telecomunicaciones en Cuba durante la llamada Actualización del Socialismo Cubano (HABEL, 2009) y del proceso de restablecimiento de las relaciones bilaterales entre Cuba y Estados Unidos, con especial enfoque en el acercamiento del Google, considerado en este artículo un actor geopolítico de los Estados Unidos, gracias a sus relaciones con el Departamento de Estado de los EEUU durante la administración de Barack Obama (ASSANGE, 2014). Cerramos este trabajo con una línea del tiempo con las acciones de la empresa en Cuba en los primeros años de los gobiernos de Miguel Díaz-Canel y Donald Trump.

Palavras clave: tecnología, internet, cuba, google 